\title{
Tubos de concreto produzidos com fibras de aço e agregados da região metropolitana de Belém do Pará
}

\author{
Steel-fiber concrete pipes and aggregates from the \\ metropolitan region of Belém do Pará
}

\section{Marco Antonio Barbosa de Oliveira Alcebíades Negrão Macêdo$$
\text { Bernardo Borges Pompeu }
$$$$
\text { Antonio Eduardo Bezerra Cabral }
$$

\section{Resumo

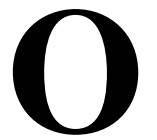

s tubos de concreto com fibras de aço apresentam-se como uma variante tecnológica interessante. No estudo incipiente na localidade, o objetivo principal é o de avaliar a viabilidade técnica de tubo de concreto de armadura descontínua com fibras de aço orientadas aleatoriamente, mediante o ensaio de compressão diametral para análise do comportamento mecânico. O objetivo secundário é o de verificar a absorção de água e o teor efetivo de fibras na ponta, no meio e na bolsa do tubo. No estudo utilizaram-se as fibras de aço DRAMIX 80/60 ou 65/35, soltas ou coladas em pente, nos teores teóricos de $0,25 \%, 0,38 \%$ e $0,50 \%$. Os resultados apontaram que apenas os tubos de concreto da série TCFA 80/60 - FCP nos teores efetivos de fibras de $0,36 \%$ e $0,50 \%$ e em todos os teores efetivos da série TCFA 80/60 - FS atingiram a mínima carga de ruptura e pós-fissuração estabelecida pela NBR 8890 (ABNT, 2007). Os resultados de absorção de água ficaram abaixo da máxima absorção recomendada pela NBR 8890 (ABNT, 2007) e houve maiores níveis de absorção e de teor efetivo de fibras na cadeia da ordem ponta, meio e bolsa. Ao final, mostrou-se oportuna a viabilidade técnica de tubo de concreto com fibras de aço na localidade.

Palavras-chave:Tubo de concreto. Fibras de aço. Compressão diametral. Absorção.

Marco Antonio Barbosa de Oliveira Instituto Federal de Educação, Ciência e Tecnologia do Pará Belém - PA - Brasil

Alcebíades Negrão Macêdo Universidade Federal do Pará Belém - PA - Brasil

Bernardo Borges Pompeu Universidade Federal do Pará Belém - PA - Brasil

Antonio Edurado Bezerra Cabral Universidade Federal do Ceará Fortaleza - CE - Brasil

Recebido em 05/01/16 Aceito em 19/02/17

\section{Abstract}

Reinforced steel-fiber concrete pipes emerge as an interesting technological variant. In an incipient study of the locality, the main objective was to assess the technical feasibility of discontinued reinforced steel-fiber concrete pipes randomly oriented by the diametrical compression test for mechanical behaviour analysis.

The second objective was to verify the water absorption and effective fiber content in the spigot, barrel and bell of the tube. In this study, DRAMIX 80/60 or 65/35 steel fibers were used (loose or glued) in the theoretical contents of $0.25 \%, 0.38 \%$ and $0.50 \%$. The results indicated that the concrete pipes from the TCFA 80/60FCP series in the effective fiber contents of $0.36 \%$ and $0.50 \%$ and the TCFA $80 / 60$ - FS series in all effective contents were the only ones that reached the minimum failure loading and post-cracking established by the NBR 8900 (ABNT, 2007). The water absorption results were below the maximum absorption recommended by NBR 8900 (ABNT, 2007) and there were higher levels of absorption and effective fiber content in the chain from the order spigot, barrel and bell. Finally, the technical feasibility of reinforced steel-fiber concrete pipes in the locality was shown to be timely.

Keywords: Concrete pipes. Steel fibers. Diametral compression. Absorption. 


\section{Introdução}

A substituição da armadura convencional com telas de aço por fibras de aço proporciona redução no tempo total de produção dos tubos, em razão da mobilidade de lançamento do concreto na forma e da mão de obra desnecessária em etapas do processo por não haver mais a montagem de telas (DE LA FUENTE et al., 2011).

Os tubos de concreto com fibras de aço apresentam menores níveis de fissuração para baixos níveis de deformação, pois as fibras atuam no início do processo de fissuração, visto que estão próximas à superfície da parede do tubo. Nos tubos de concreto com fibras de aço sem a armadura convencional com telas ou vergalhões não é necessário cobrimento mínimo e posicionamento próximo à linha neutra na parte central da parede do tubo de concreto (FIGUEIREDO, 2011).

Os tubos com fibras de aço podem trabalhar de maneira semelhante ou superior aos tubos de concreto armado com barras tradicionais, principalmente no estado limite de utilização ou serviço, tendo em vista que dificultam com maior intensidade a propagação das fissuras nesse estágio (DE LA FUENTE et al., 2011). O comportamento apresentado pelos tubos de concreto com fibras no estado limite de utilização é relevante, haja vista que o maior interesse de aplicação recai nesse estágio, que remete aos critérios de durabilidade do componente (FIGUEIREDO, 2011).

A NBR 8890 (ABNT, 2007), apresenta as fibras de aço como reforço para tubo de concreto. Para serem utilizadas como reforços no tubo de concreto devem ser de aço trefilado com resistência à tração mínima de $1.000 \mathrm{kgf}$ com ancoragem em gancho e fator de forma mínimo de 40, caracterizando uma fibra do tipo AI. Chama Neto (2002) e Figueiredo e Torneli (2006), em pesquisas anteriores, obtiveram melhores resultados de resistência para a fibra do tipo AI, quando aplicadas como reforço nos tubos de concreto.

A NBR 8890 (ABNT, 2007) estabelece que a relação água/cimento, expressa em litros por quilograma, deve ser de 0,50 e 0,45 para tubos destinados a águas pluviais e a esgotos sanitários, respectivamente. A dimensão máxima característica dos agregados deve possuir o menor valor entre um terço da espessura do tubo e o cobrimento mínimo da armadura. Os tubos de concreto reforçados com fibras têm o controle realizado diretamente no tubo por meio do ensaio de compressão diametral. O ensaio de compressão diametral determina a capacidade resistente e a partir disso ocorre a classificação dos tubos (FIGUEIREDO, 2011).

\section{Significância da pesquisa}

Estudos anteriores têm investigado aspectos do comportamento mecânico, durabilidade e viabilidade técnica do tubo de concreto reforçado com fibras de aço (por exemplo, Figueiredo et al. (2007), de la Fuente et al. (2011), Mohsen (2014), e Mohamed (2015)). No entanto, entre as dificuldades de aplicação do tubo de concreto de armadura descontínua com fibras de aço tem-se as restrições de recomendações normativas e código de projeto estrutural. Desse modo, novos estudos são imprescindíveis na construção dessa alternativa tecnológica. Este estudo vem contribuir com a iniciativa na localidade para a fabricação de tubos de concreto de armadura descontínua com fibras de aço orientadas aleatoriamente, visando a viabilidade técnica, a partir de ensaios para avaliação do comportamento mecânico e da durabilidade. No ensaio de durabilidade houve a análise da absorção de água na região da ponta, meio e bolsa do tubo. Em cada região do tubo descrita anteriormente ocorreu a verificação do teor efetivo de fibras incorporadas no tubo de concreto, com correlações da resposta mecânica e de absorção com teores efetivos de fibras.

O objetivo geral do estudo visa avaliar a viabilidade técnica na localidade de tubo de concreto de armadura descontínua com fibras de aço orientadas aleatoriamente, a partir da substituição integral da armadura contínua convencional.

Os objetivos secundários remetem a:

(a) analisar a absorção de água e o teor efetivo de fibras nas amostras das faixas e da região da ponta, meio e bolsa do tubo;

(b) verificar a dispersão dos resultados de absorção de água e teor efetivo de fibras; e

(c) abordar a reologia de concreto de consistência seca com fibras de aço.

\section{Método experimental}

A metodologia experimental utilizou parâmetros, características e variáveis a partir do estado da arte e recomendação do fabricante.

\section{Materiais}

No procedimento experimental foi utilizado o cimento Portland, composto resistente a sulfatos 
do tipo CP II-Z-32 RS, conforme a NBR 11578 (ABNT, 1997), agregados miúdos (areia fina) e agregados graúdos (seixo de rio), de acordo com a NBR 7211 (ABNT, 2009c). As fibras de aço foram utilizadas no estado coladas em pente e soltas da DRAMIX $^{\circledR} 3$ D do tipo $65 / 35$ ou $80 / 60$, conforme as Figuras 1a e 1b, respectivamente.

A massa específica do cimento conforme a NBR NM 23 (ABNT, 2001) foi fornecida pelo fabricante. Foi obtida a massa específica do agregado miúdo, segundo a NBR NM 52 (ABNT, 2009a), do agregado graúdo, segundo a NBR NM
53 (ABNT, 2009b), e da massa unitária para o agregado miúdo e graúdo, em consonância com a NBR NM 45 (ABNT, 2006), que estão apresentados conforme a Tabela 1. A determinação da composição granulométrica dos agregados miúdos e graúdos ocorreu em conformidade com a NBR NM 248 (ABNT, 2003). As características físicas do agregado miúdo e graúdo estão apresentadas conforme as Tabelas 2 e 3 , es características físico-mecânicas das fibras de aço conforme a Tabela 4.

Figura 1 - (a) Fibras de aço coladas em pente e (b) fibras de aço soltas

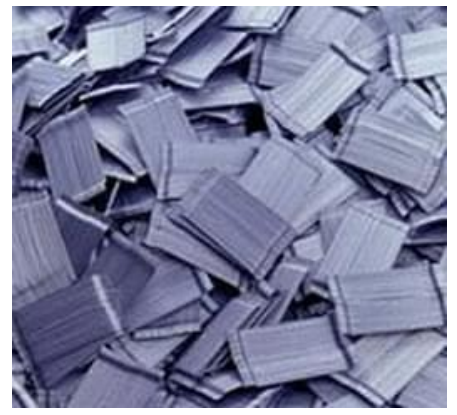

(a)

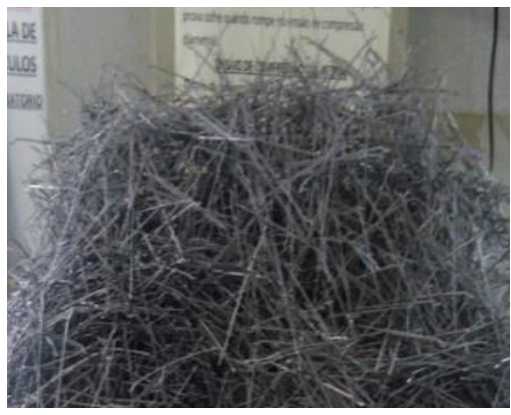

(b)

Tabela 1 - Caracterização física dos materiais

\begin{tabular}{c|c|c}
\hline Material & Massa unitária $\left(\mathbf{g} / \mathbf{c m}^{3}\right)$ & Massa específica $\left(\mathbf{g} / \mathbf{c m}^{\mathbf{3}}\right)$ \\
\hline Cimento CP II-Z-32 RS & - & 3,02 \\
Areia fina & 1,46 & 2,63 \\
Seixo de rio & 1,56 & 2,53 \\
\hline
\end{tabular}

Tabela 2 - Características físicas do agregado miúdo

\begin{tabular}{c|c}
\hline Diâmetro máximo $(\mathrm{mm})$ & 1,20 \\
\hline Módulo de finura & 2,03 \\
\hline
\end{tabular}

Tabela 3 - Características físicas do agregado graúdo

\begin{tabular}{c|c}
\hline Diâmetro máximo $(\mathrm{mm})$ & 12,5 \\
\hline Módulo de finura & 4,93 \\
\hline
\end{tabular}

Tabela 4 - Características físico-mecânicas das fibras de aço

\begin{tabular}{c|c|c|c|c}
\hline \multicolumn{3}{c|}{ Dimensões } & \multirow{2}{E}{} & \multirow{2}{*}{$\begin{array}{c}\boldsymbol{f}_{\boldsymbol{t}} \\
(\mathbf{M p a})\end{array}$} \\
\hline $\boldsymbol{l}_{\boldsymbol{f}}(\mathbf{m m})$ & $\boldsymbol{d}_{f}(\mathbf{m m})$ & $\frac{\boldsymbol{l}_{\boldsymbol{f}}}{\boldsymbol{d}_{\boldsymbol{f}}}$ & $(\mathbf{G P a})$ & 1100 \\
\hline 60 & 0,75 & 80 & 210 & 1150 \\
\hline
\end{tabular}

Nota: Legenda:

$l_{f}$ - comprimento da fibra de aço;

$d_{f}$ - diâmetro da fibra de aço;

$\frac{l_{f}}{d_{f}}$ - fator de forma da fibra de aço;

$\mathrm{E}$ - módulo de elasticidade; e

$f_{t^{-}}$resistência à tração da fibra e aço. 


\section{Detalhes da amostra}

Os tubos de concreto de referência (sem armadura contínua e descontínua) possuem classe de resistência equivalente a PS1. Os tubos de concreto de armadura contínua convencional e descontínua com fibras de aço orientadas aleatoriamente dessa pesquisa são destinados a águas pluviais e de classe de resistência PA1. Os tubos de concreto de armadura contínua convencional foram moldados com tela metálica do tipo PB - 246 com malha de $10 \mathrm{~cm}$ x $20 \mathrm{~cm}$ e fios CA - 60 de $5.6 \mathrm{~mm} \times 3.4$ $\mathrm{mm}$, respectivamente.

A ilustração e geometria do tubo de concreto com as dimensões estão apresentadas conforme a Figura 2.

\section{Dosagens das amostras}

Na produção dos tubos de concreto com fibras de aço utilizou-se o mesmo consumo de cimento, relação água/cimento $(\mathrm{a} / \mathrm{c})$ e dosagem de concreto (traço), que era rotineiramente utilizada pela empresa para produção de tubos de concreto de referência e de armadura contínua convencional com tela metálica. Não houve a utilização de aditivos na produção de todos os tubos de concreto. A dosagem da fibra de aço foi obtida pela regra da mistura em compósitos reforçados com fibras (ASKELAND; WRIGTH, 2014). As nomenclaturas de dosagens do concreto e das fibras de aço estão apresentadas conforme as Tabelas 5 e 6 .

Figura 2 - Especificação do tubo de concreto
O número de amostra de um tubo de concreto da série TCFA para cada variável deve-se aos resultados dos ensaios preliminares para obtenção de tração indireta, fator de tenacidade e resistência residual em corpos de prova, que apresentaram analogia com resultados de estudos anteriores, e tendência similar com os resultados de comportamento dos primeiros tubos de concreto da série TCFA. Os resultados de resistência média dos ensaios preliminares estão apresentados na Tabela 7. Outro fator foi a limitação orçamentária e de produção dos tubos de concreto.

\section{Processos de mistura e moldagem das amostras}

O processo de mistura e os equipamentos utilizados nesse estudo são iguais para todos os tubos de concreto produzidos. O processo de mistura e moldagem dos tubos de concreto ocorreu nas instalações de uma empresa da região que atua no segmento de tubos pré-moldados. O processamento da mistura da areia, seixo e cimento ocorreu na betoneira, e são adicionadas progressivamente a água e as fibras de aço, no caso de tubo de concreto de armadura descontínua com fibras de aço (série TCFA). Posteriormente, a mistura é lançada na esteira de alimentação e transportada até um conjunto vibratório, conforme a Figura 3.

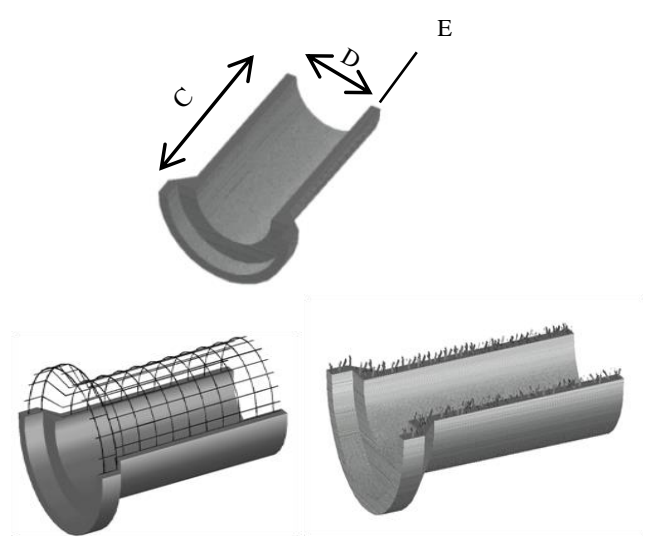

\begin{tabular}{ccc}
\hline \multicolumn{3}{c}{ Especificações do tubo } \\
\hline Código & Significado & Dimensões \\
D & Diâmetro (mm) & 600 \\
C & Comprimento & 1000 \\
& $\begin{array}{c}(\mathrm{mm}) \\
\text { E }\end{array}$ & Espessura (mm) \\
\hline
\end{tabular}

144 Oliveira, M. A. B. de; Macêdo, A. N.; Pompeu, B. B. Cabral, A. E. B. 
Tabela 5 - Dosagem do concreto (traço)

\begin{tabular}{c|c|c|c}
\hline $\begin{array}{c}\text { Traço unitário em massa } \\
\left(\mathbf{c}: \mathbf{a g m}: \mathbf{a g}_{\mathbf{g}}\right)\end{array}$ & Relação a/c & $\begin{array}{c}\text { Consumo de cimento } \\
\left(\mathbf{k g} / \mathbf{m}^{\mathbf{3}}\right)\end{array}$ & $\begin{array}{c}\text { Teor de argamassa } \\
(\mathbf{\%})\end{array}$ \\
\hline $1: 2,30: 2,46$ & 0,32 & 395 & 57,3 \\
\hline
\end{tabular}

Nota: Legenda:

c - cimento;

agm - agregado miúdo (areia);

$\mathrm{agg}_{\mathrm{g}}$ - agregado graúdo (seixo); e

a/c - água/cimento.

Tabela 6 - Dosagem teórica das fibras

\begin{tabular}{|c|c|c|c|}
\hline \multirow{2}{*}{ Série } & \multicolumn{2}{|c|}{ Teor teórico } & \multirow{2}{*}{ Número de amostra } \\
\hline & $\left(\mathrm{kg} / \mathrm{m}^{3}\right)$ & $\%$ & \\
\hline TCS & - & - & 2 \\
\hline TCA & - & - & 2 \\
\hline \multirow{3}{*}{ TCFA $65 / 35-$ FCP } & 20 & 0,25 & 1 \\
\hline & 30 & 0,38 & 1 \\
\hline & 40 & 0,50 & 1 \\
\hline \multirow{3}{*}{ TCFA $65 / 35-F S$} & 20 & 0,25 & 1 \\
\hline & 30 & 0,38 & 1 \\
\hline & 40 & 0,50 & 1 \\
\hline \multirow{3}{*}{ TCFA $80 / 60-F C P$} & 20 & 0,25 & 1 \\
\hline & 30 & 0,38 & 1 \\
\hline & 40 & 0,50 & 1 \\
\hline \multirow{3}{*}{ TCFA $80 / 60-F S$} & 20 & 0,25 & 1 \\
\hline & 30 & 0,38 & 1 \\
\hline & 40 & 0,50 & 1 \\
\hline
\end{tabular}

Nota: Legenda:

TCS - Tubo de concreto de referência (sem armadura contínua e descontínua);

TCA - Tubo de concreto de armadura contínua convencional;

TCFA - Tubo de concreto de armadura descontínua com fibras de aço;

FS - Fibras de aço no estado soltas; e

FCP - Fibras de aço no estado coladas em pente.

Tabela 7 - Caracterização física dos materiais

\begin{tabular}{|c|c|c|c|c|}
\hline Série & $\begin{array}{c}\text { Teor teórico } \\
\left(\mathrm{kg} / \mathrm{m}^{3}\right)\end{array}$ & $\begin{array}{c}\text { Tração indireta } \\
\text { médio (MPa) }\end{array}$ & $\begin{array}{c}\text { FT } \\
\text { médio } \\
\text { (MPa) }\end{array}$ & $\begin{array}{c}\text { Resistência } \\
\text { residual médio - } \\
f r, 4-(\mathrm{MPa})\end{array}$ \\
\hline \multirow{3}{*}{ TCFA 65/35-FCP } & 20 & 3,2 & 0,8 & 0,7 \\
\hline & 30 & 3,4 & 1,9 & 2,0 \\
\hline & 40 & 3,6 & 2,1 & 2,1 \\
\hline \multirow{3}{*}{ TCFA $65 / 35$-FS } & 20 & 3,0 & 2,3 & 2,1 \\
\hline & 30 & 3,2 & 2,3 & 3,7 \\
\hline & 40 & 3,3 & 2,9 & 4,2 \\
\hline \multirow{3}{*}{ TCFA 80/60-FCP } & 20 & 4,4 & 2,1 & 2,0 \\
\hline & 30 & 4,5 & 3,3 & 2,2 \\
\hline & 40 & 4,6 & 3,6 & 3,9 \\
\hline \multirow{3}{*}{ TCFA 80/60-FS } & 20 & 3,4 & 2,3 & 3,6 \\
\hline & 30 & 3,8 & 3,3 & 3,7 \\
\hline & 40 & 4,0 & 4,1 & 4,1 \\
\hline \multicolumn{2}{|c|}{ Método de ensaio } & NBR 7222 & $\begin{array}{l}\text { JSCE } \\
\text { SF-04 }\end{array}$ & $\begin{array}{l}\text { RILEM TC 162- } \\
\text { TDF }\end{array}$ \\
\hline
\end{tabular}


Figura 3 - Processo de mistura e moldagem

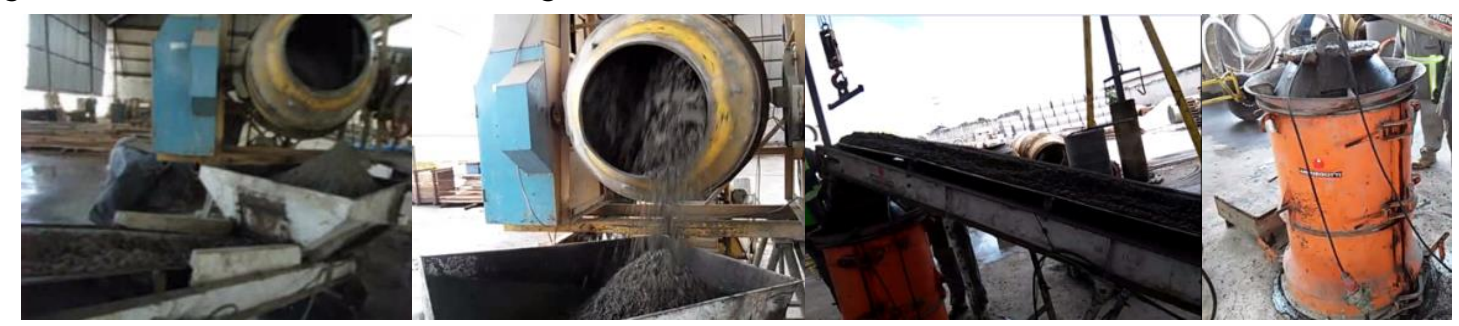

Esse equipamento realiza a moldagem e compactação, e é constituído por duas formas laterais, um anel da base de apoio e um cilindro hidráulico vibratório que promove uma rotação de alta velocidade com o intuito de proporcionar compressão radial do material junto às paredes do interior das formas.

Na localidade do estudo a utilização desse tipo de equipamento é comum para fabricação de tubos de concreto da série TCS e TCA, no entanto para produção de tubos de concreto da série TCFA teve caráter embrionário. No Brasil tem-se conhecimento de poucos estudos com a utilização desse tipo de equipamento para a produção de tubos de concreto de armadura descontínua com fibras de aço.

Nos tubos de concreto da série TCA ocorreu a montagem da armadura de tela metálica de forma manual. A armadura é colocada sobre o anel da base que funciona como tampa inferior e apoio do tubo desformado. Após desforma do tubo recémmoldado ocorre acabamento superficial e transporte para local onde permaneceu em cura por 28 dias.

\section{Métodos de ensaio}

Para a avaliação do concreto no estado fresco foi realizado o ensaio de determinação da consistência pelo abatimento de tronco de cone, conforme a NBR NM 67 (ABNT, 1998).

Os tubos de concreto de referência, de armadura contínua convencional e descontínua com fibras de aço para avaliação do comportamento mecânico e durabilidade foram submetidos, respectivamente, aos ensaios de compressão diametral e de absorção de água, conforme a NBR 8890 (ABNT, 2007), e quanto à verificação do teor efetivo de fibras, de acordo com método proposto por Kalil, Escariz e Figueiredo (2010). Para o ensaio de absorção de água e verificação do teor efetivo de fibras houve a retirada de duas faixas da parede de cada variável de tubo de concreto da série TCFA analisados, sendo em cada faixa realizada a extração de corpos de prova da região da ponta, meio e bolsa, conforme apresentado na Tabela 8 .

Para a verificação de teor efetivo de fibras houve a trituração das amostras sobre um recipiente e posteriormente a extração das fibras de aço que ocorreu com uso de ímã. Em seguida houve a separação e o acondicionamento em saco plástico identificado para pesagem e obtenção do teor efetivo de fibras a partir da relação da massa pelo volume da amostra.

No ensaio de compressão diametral dos tubos de concreto de referência, torna-se necessário obter apenas a carga de ruptura, tendo em vista o comportamento frágil.

Para os tubos de concreto de armadura contínua convencional há exigência da determinação da carga de fissura e ruptura. Os tubos de concreto de referência e armadura contínua convencional são submetidos ao ensaio de carregamento contínuo.

Os tubos de concreto de armadura descontínua com fibras de aço foram submetidos ao ensaio de carregamento cíclico para obtenção no primeiro ciclo da carga isenta de dano e da carga de ruptura e no segundo ciclo da carga mínima pósfissuração, que deve ter um valor de 5\% acima do obtido para a carga isenta de dano.

\section{Instrumentação}

De acordo com a NBR 8890 (ABNT, 2007), os tubos de concreto foram submetidos ao método dos três cutelos, sendo apoiados sobre dois cutelos de madeira separados entre si, e o terceiro cutelo correspondeu a uma viga metálica que foi colocada ao longo da geratriz superior do tubo, excluindo a bolsa do tubo. Todos os cutelos foram colocados no sentido paralelo ao eixo longitudinal do tubo para que haja uma distribuição uniforme do carregamento. Entre os cutelos inferiores ou superiores e a superfície do tubo foi colocada uma tira de borracha para não haver concentração de tensões em determinadas regiões do tubo ocasionadas por irregularidades na superfície do tubo.

146 Oliveira, M. A. B. de; Macêdo, A. N.; Pompeu, B. B. Cabral, A. E. B. 
Tabela 8 - Nomenclatura das faixas e corpos de prova dos tubos

\begin{tabular}{|c|c|c|c|c|c|}
\hline \multirow{2}{*}{ Série } & \multirow{2}{*}{$\begin{array}{c}\text { Teor teórico } \\
\left(\mathrm{Kg} / \mathbf{m}^{3}\right)\end{array}$} & \multicolumn{4}{|c|}{ Amostra do tubo } \\
\hline & & Faixa & $\mathbf{P}$ & $\mathbf{M}$ & B \\
\hline \multirow{6}{*}{$\begin{array}{c}\text { TCFA } 65 / 35- \\
\text { FCP }\end{array}$} & \multirow{2}{*}{20} & FA & FA1 & FA2 & FA3 \\
\hline & & FB & FB4 & FB5 & FB6 \\
\hline & \multirow{2}{*}{30} & FC & FC7 & FC8 & FC9 \\
\hline & & FD & FD10 & FD11 & FD12 \\
\hline & \multirow{2}{*}{40} & FE & FE13 & FE14 & FE15 \\
\hline & & FF & FF16 & FF17 & FF18 \\
\hline \multirow{6}{*}{$\begin{array}{c}\text { TCFA } 65 / 35- \\
\text { FS }\end{array}$} & \multirow{2}{*}{20} & FG & FG19 & FG20 & FG21 \\
\hline & & $\mathrm{FH}$ & FH 22 & FH 23 & FH24 \\
\hline & \multirow{2}{*}{30} & FI & FI25 & FI26 & FI27 \\
\hline & & FJ & FJ28 & FJ29 & FJ30 \\
\hline & \multirow{2}{*}{40} & FK & FK31 & FK32 & FK33 \\
\hline & & FL & FL34 & FL35 & FL36 \\
\hline \multirow{6}{*}{$\begin{array}{c}\text { TCFA 80/60 - } \\
\text { FCP }\end{array}$} & \multirow{2}{*}{20} & FM & FM37 & FM38 & FM39 \\
\hline & & FN & FN40 & FN41 & FN42 \\
\hline & \multirow{2}{*}{30} & FO & FO43 & FO44 & FA45 \\
\hline & & FP & FP46 & FP47 & FP48 \\
\hline & \multirow{2}{*}{40} & $\mathrm{FQ}$ & FQ49 & FQ50 & FQ51 \\
\hline & & FR & FR52 & FR53 & FR54 \\
\hline \multirow{6}{*}{$\begin{array}{c}\text { TCFA } 80 / 60- \\
\text { FS }\end{array}$} & \multirow{2}{*}{20} & FS & FS55 & FS56 & FS57 \\
\hline & & FT & FT58 & FT59 & FT60 \\
\hline & \multirow{2}{*}{30} & FU & FU61 & FU62 & FU63 \\
\hline & & $\mathrm{FV}$ & FV64 & FV65 & FV66 \\
\hline & \multirow{2}{*}{40} & FW & FW67 & FW68 & FW69 \\
\hline & & FX & FX70 & FX71 & FX72 \\
\hline
\end{tabular}

Nota: Legenda:

$$
\begin{aligned}
& \text { P - Ponta do tubo; } \\
& \text { M - Meio do tubo; e } \\
& \text { B - Bolsa do tubo. }
\end{aligned}
$$

Apesar de a NBR 8890 (ABNT, 2007) não exigir a leitura do deslocamento diametral, foi utilizado um relógio comparador digital de alta precisão para a leitura do deslocamento vertical diametral, sendo posicionado na geratriz superior da ponta do tubo, pois a região da bolsa do tubo tem uma contribuição mais intensa da matriz de concreto no prolongamento do trecho elástico inicial da curva carga versus deformação diametral (SILVA; EL DEBS, 2009). Desse modo, a medida de deslocamento diametral somente na ponta minimiza a influência da bolsa no comportamento do tubo (SILVA, 2011), e a avaliação de compressão diametral apenas na ponta do tubo garante maior fator de segurança (DE LA FUENTE et al., 2011). A instrumentação dos tubos está demonstrada conforme a Figura 4.

\section{Procedimento do ensaio}

A leitura da carga aplicada foi verificada no indicador de pesagem acoplado a uma célula de carga de 50 t que fica intercalada entre a viga de reação do pórtico e o pistão do macaco hidráulico com capacidade de $95 \mathrm{t}$. A leitura do deslocamento vertical diametral na geratriz superior da ponta do tubo foi realizada por relógio comparador digital de alta precisão acoplado no suporte com base magnética, fixada no apoio metálico.

A aplicação de carga no macaco hidráulico ocorreu seguindo uma metodologia em que a cada um passe de carga de $200 \mathrm{~kg}$ era verificado o tempo no relógio comum e o deslocamento vertical diametral no relógio comparador digital. A leitura do tempo foi verificada em segundos, e posteriormente foi convertida para minutos para obtenção do gráfico de carga versus tempo. 
Figura 4 - Posicionamento dos equipamentos

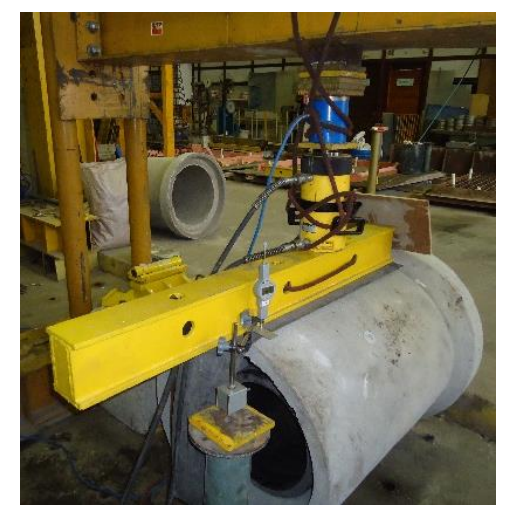

\section{Resultados e discussão}

Os resultados de consistência do concreto apresentaram abatimento de tronco de cone de 0 $\mathrm{mm}$ em todas as amostras, indicando consistência adequada para a produção de tubos.

A partir desse momento serão adotados os resultados obtidos de teores efetivos de fibras, conforme apresentados na Tabela 9, para a análise de resultados de compressão diametral e absorção de água dos tubos.

\section{Plano de fissuramento dos tubos}

O plano de fissuramento dos tubos seguiu o padrão esperado com quatro principais rotulações, sendo coroa, base e flancos esquerdo e direito, conforme as Figuras 5 e 6, de maneira semelhante aos resultados obtidos no modelo proposto por de la Fuente et al. (2011).

As fissuras começam na região da ponta dos tubos e propagam-se para a região da bolsa. Isso ocorre devido ao menor limite de deformação elástica do concreto na ponta. Devido aos esforços de flexão, ocorrem fissuras longitudinais primeiramente na borda interna da coroa, definida como fase fissurada, e posteriormente na fase pré-ruptura ocorrem fissuras longitudinais nas bordas internas da base e externas dos flancos direito e esquerdo dos tubos (DE LA FUENTE et al., 2011).

A ruptura dos tubos de concreto de referência ocorreu de maneira frágil, não havendo sinais de resistência residual, ou seja, ocorreu o colapso do tubo ao atingir a carga de ruptura. Esse comportamento era esperado por ser apenas concreto de referência, sem armadura. Todos os tubos de concreto de armadura contínua convencional e descontínua com fibras de aço suportaram o carregamento sem entrar em colapso após atingir a carga de ruptura, apresentando resistência residual.

\section{Compressão diametral dos tubos}

A partir do ensaio de compressão diametral foram determinadas as cargas dos tubos de concreto da série TCS, TCA e TCFA, definidas pelas curvas de carga versus tempo, conforme mostram as Figuras 7 a 12 .

Tabela 9 - Teor efetivo de fibras

\begin{tabular}{|c|c|c|c|c|c|c|}
\hline \multirow[t]{2}{*}{ Série } & \multirow[t]{2}{*}{ Tipo } & \multirow[t]{2}{*}{ Estado } & \multicolumn{2}{|c|}{ Teor teórico } & \multicolumn{2}{|c|}{$\begin{array}{c}\text { Teor } \\
\text { efetivo médio }\end{array}$} \\
\hline & & & $\left(\mathrm{kg} / \mathrm{m}^{3}\right)$ & $(\%)$ & $\left(\mathrm{kg} / \mathrm{m}^{3}\right)$ & $(\%)$ \\
\hline \multirow{12}{*}{ TCFA } & \multirow{6}{*}{$65 / 35$} & \multirow{3}{*}{$\mathrm{FCP}$} & 20 & 0,25 & 17,5 & 0,23 \\
\hline & & & 30 & 0,38 & 27,4 & 0,37 \\
\hline & & & 40 & 0,50 & 38,3 & 0,51 \\
\hline & & \multirow{3}{*}{ FS } & 20 & 0,25 & 18,7 & 0,25 \\
\hline & & & 30 & 0,38 & 28,6 & 0,38 \\
\hline & & & 40 & 0,50 & 38,8 & 0,52 \\
\hline & \multirow{6}{*}{$80 / 60$} & \multirow{3}{*}{ FCP } & 20 & 0,25 & 17,6 & 0,23 \\
\hline & & & 30 & 0,38 & 27,0 & 0,36 \\
\hline & & & 40 & 0,50 & 37,8 & 0,50 \\
\hline & & \multirow{3}{*}{ FS } & 20 & 0,25 & 18,8 & 0,25 \\
\hline & & & 30 & 0,38 & 28,5 & 0,38 \\
\hline & & & 40 & 0,50 & 39,0 & 0,52 \\
\hline
\end{tabular}

148 Oliveira, M. A. B. de; Macêdo, A. N.; Pompeu, B. B. Cabral, A. E. B. 


\section{Figura 5 - Configuração das rotulações}

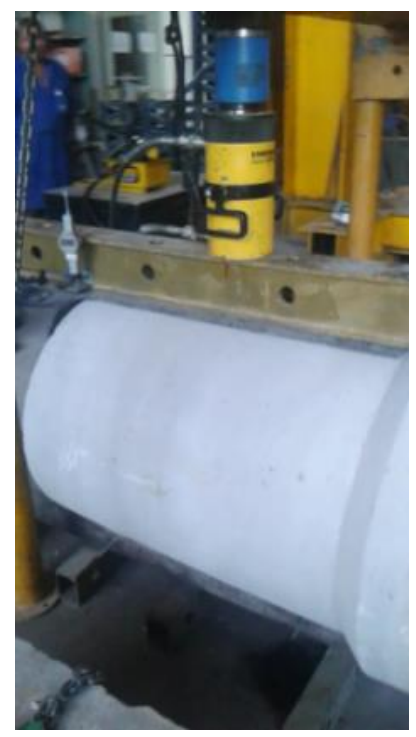

Figura 6 - Plano de fissuração do tubo

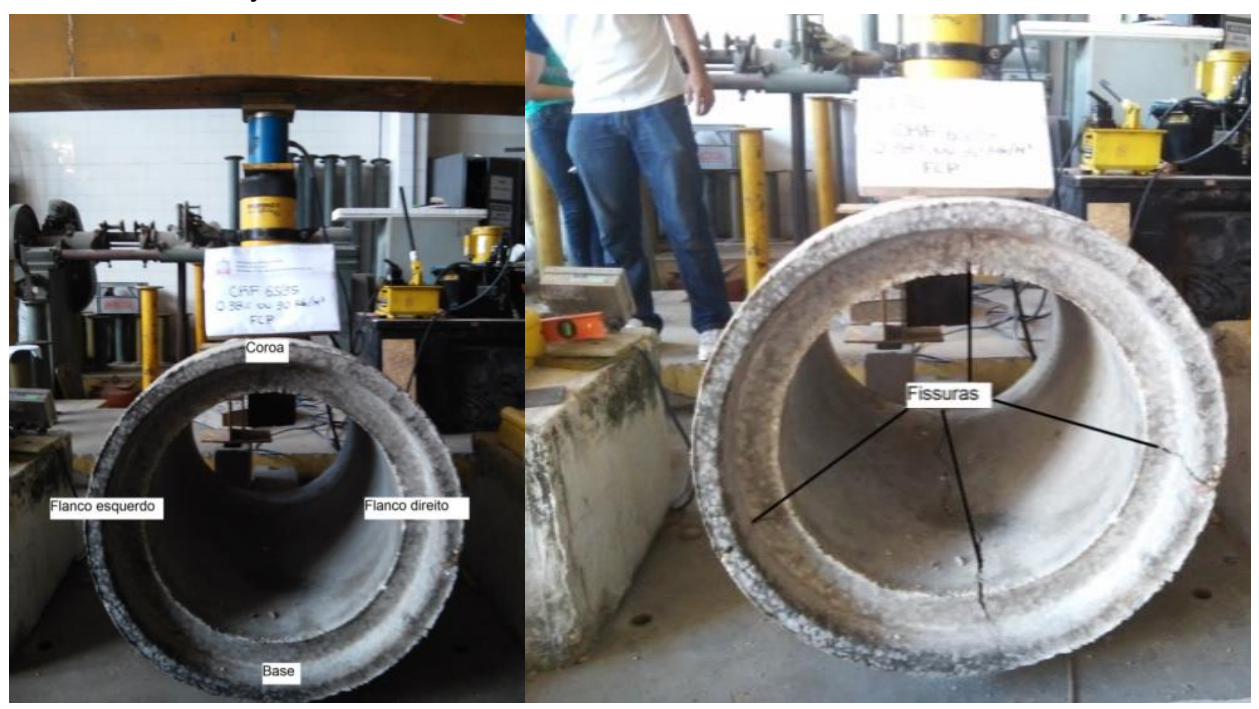

Figura 7 - Curvas de carga versus tempo da série TCS - médio

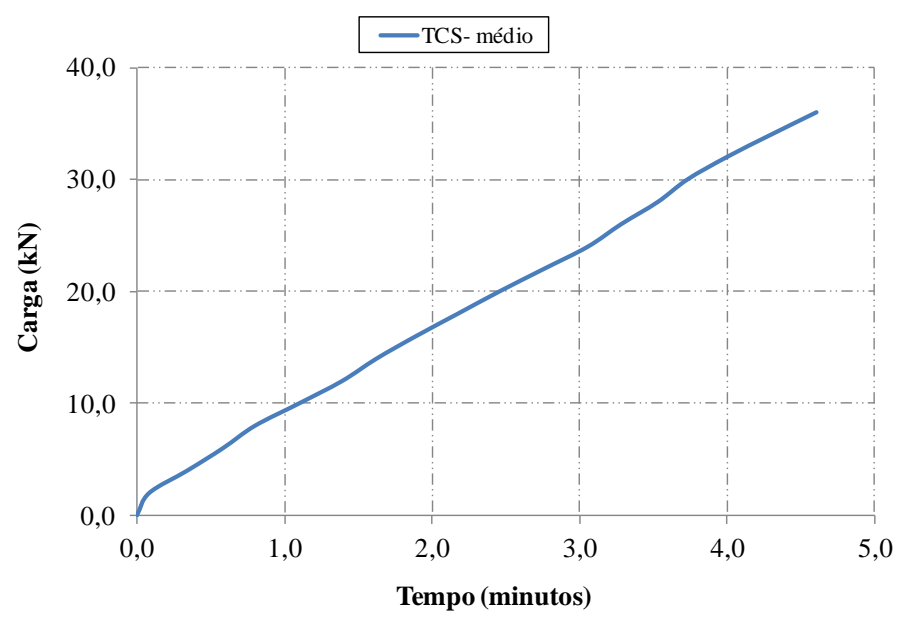


Figura 8 - Curvas de carga versus tempo da série TCA - médio

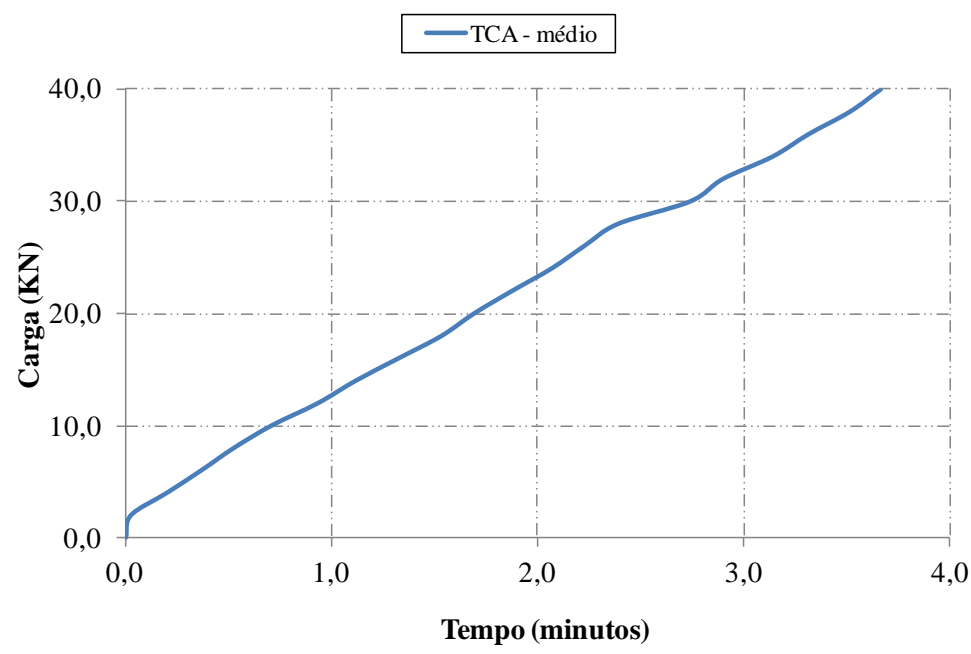

Figura 9 - Curvas de carga versus tempo da série TCFA 65/35 FCP

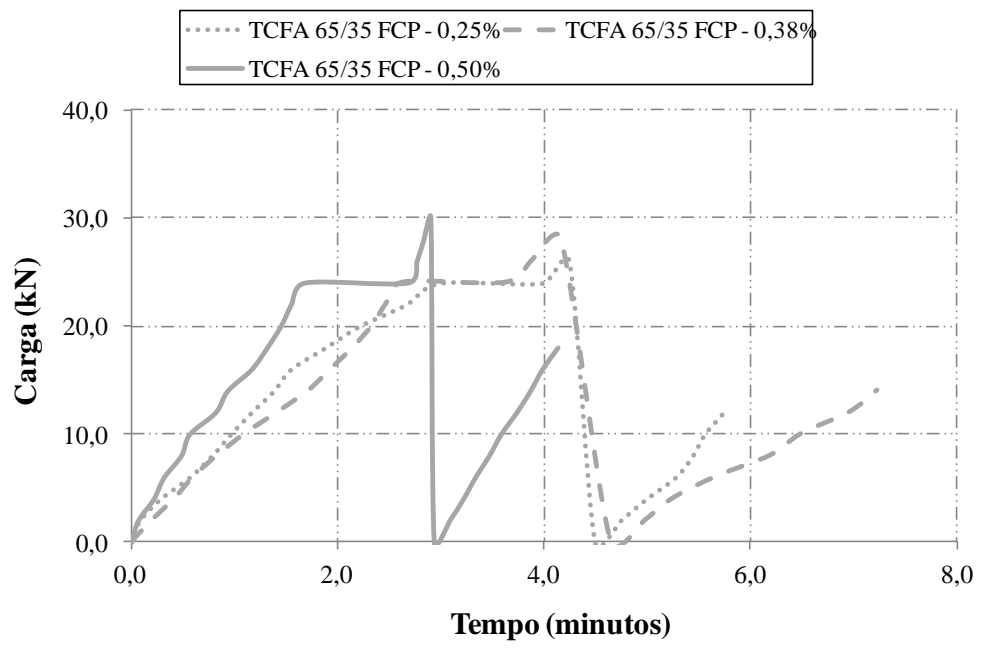

Figura 10 - Curvas de carga versus tempo da série TCFA 65/35 FS

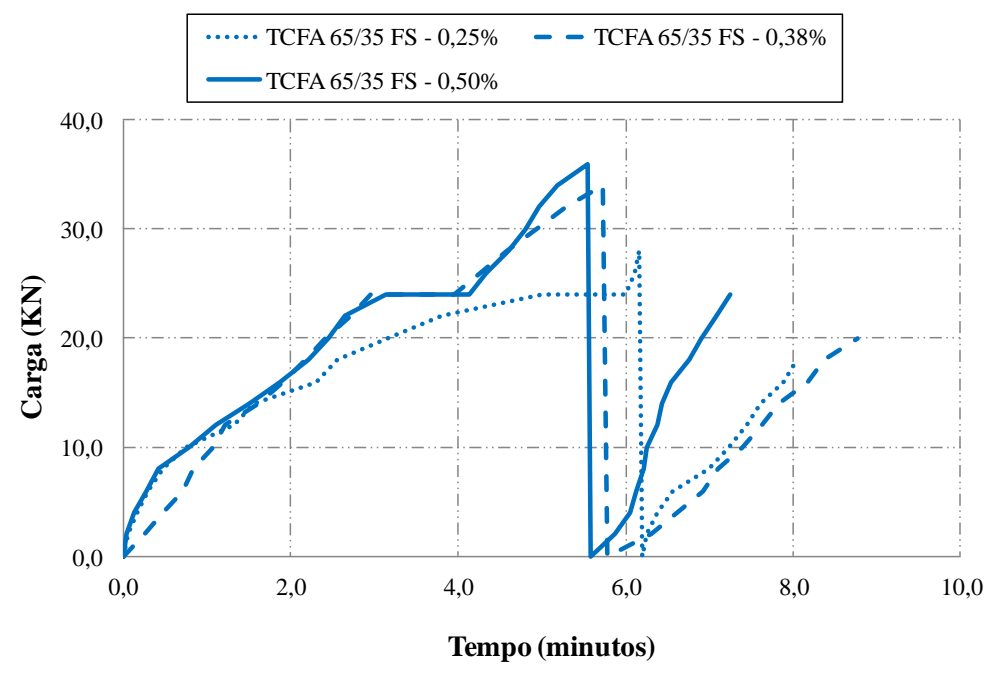

150 Oliveira, M. A. B. de; Macêdo, A. N.; Pompeu, B. B. Cabral, A. E. B. 
Figura 11 - Curvas de carga versus tempo da série TCFA 80/60 FCP

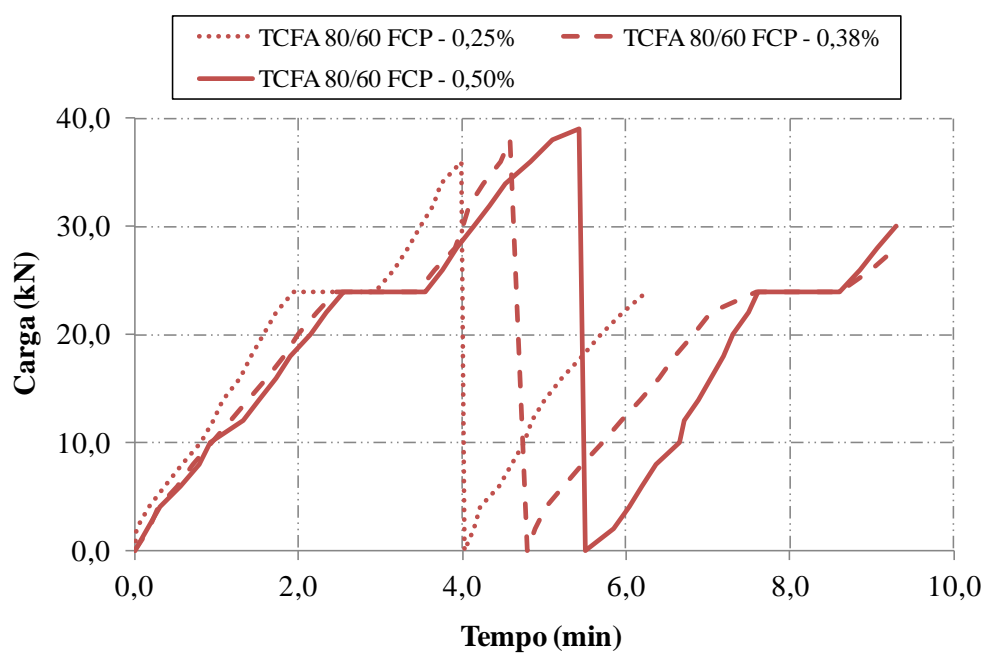

Figura 12 - Curvas de carga versus tempo da série TCFA 80/60 FS

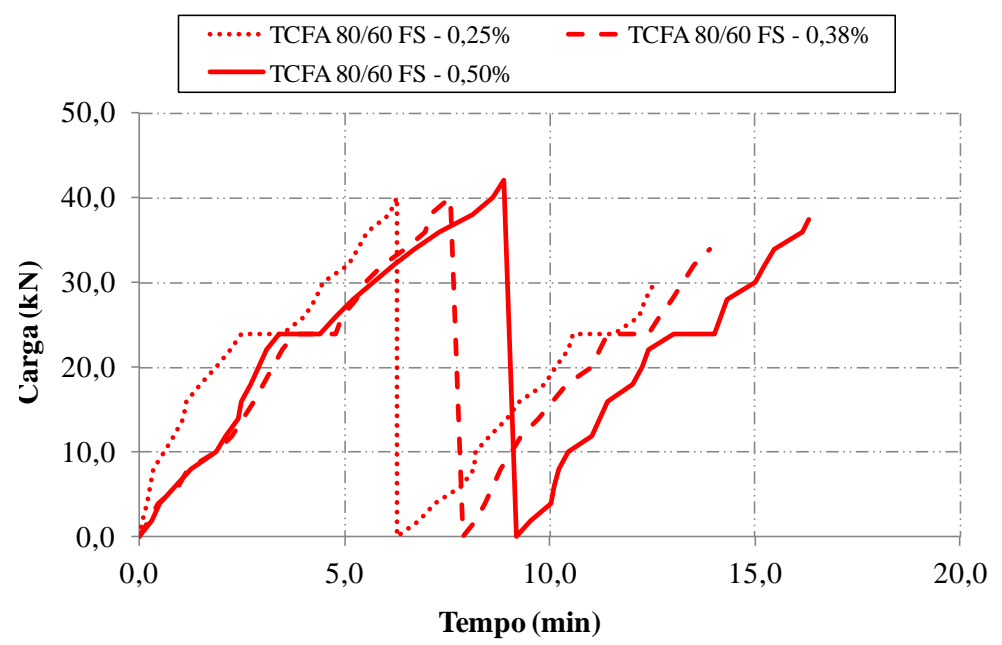

Os resultados das cargas obtidas no ensaio de compressão diametral estão apresentados na Tabela 10. De acordo com a Tabela 10, verifica-se que os tubos de concreto de referência atingiram carga mínima de ruptura estabelecida pela NBR 8890 (ABNT, 2007).

Os tubos de concreto da série TCA atingiram a mínima carga de fissura e ruptura estabelecida pela NBR 8890, superando em $33 \%$ e $11 \%$ a carga mínima de fissura e de ruptura, respectivamente. Os tubos de concreto da série TCFA 65/35 FCP em todos os teores de fibras não alcançaram o mínimo da carga isenta de dano e de ruptura, preconizado pela NBR 8890.

Os tubos de concreto da série TCFA - 80/60 - FCP em todos os teores atingiram a carga de ruptura, sendo apenas o TCFA 80/60 com 0,23\% que não alcançou a carga mínima de pós-fissuração de 25,2 $\mathrm{KN} / \mathrm{m}$. No estudo realizado por Escariz (2012), para três amostras houve apenas um tubo com fibras coladas em pente do tipo 80/60 no teor de 25 $\mathrm{kg} / \mathrm{m}^{3}(0,32 \%)$ que atingiu as cargas de ruptura e pós-fissuração mínimas. Os tubos de concreto da série TCFA - 65/35 - FS somente nos teores de $0,38 \%$ e $0,52 \%$ atingiram a carga mínima de ruptura, mas não alcançaram a carga mínima de pós-fissuração.

Os tubos de concreto da série TCFA - 80/60 - FS atingiram a mínima carga de ruptura e pósfissuração em todos os teores analisados, e o tubo de concreto da série TCFA - 80/60 - FS no teor efetivo de $0,52 \%$ uma carga de ruptura e máxima pós-fissuração que superaram em $17 \%$ e $49 \%$ a mínima carga de ruptura e pós-fissuração, respectivamente. Nessa série a carga máxima pósfissuração teve um resultado próximo da carga de ruptura, o que demonstra um ótimo desempenho da fibra no estágio pós-fissuração. 
Tabela 10 - Resultados de compressão diametral

\begin{tabular}{c|c|c|c|c|c}
\hline \multirow{2}{*}{ Série } & \multirow{2}{*}{$\begin{array}{c}\text { Teor efetivo } \\
\text { médio }\left(\mathbf{k g} / \mathbf{m}^{3}\right)\end{array}$} & \multicolumn{2}{c|}{$\begin{array}{c}\text { Cargas obtidas } \\
\text { (KN/m) }\end{array}$} & \multicolumn{2}{c}{$\begin{array}{c}\text { Cargas mínimas da } \\
\text { NBR 8890 (KN/m) }\end{array}$} \\
\cline { 3 - 6 } & $\mathbf{C R}$ & $\mathbf{C M F} / \mathbf{C M P F}$ & $\mathbf{C m F / C I D}$ & $\mathbf{C m R}$ \\
\hline TCS & - & 36 & - & - & 24 \\
\hline TCA & - & 40 & 32 & 24 & 36 \\
\hline \multirow{2}{*}{ TCFA } & 0,23 & 27 & 12 & 24 & 36 \\
65/35-FCP & 0,37 & 28 & 14 & 24 & 36 \\
& 0,51 & 30 & 18 & 24 & 36 \\
\hline \multirow{2}{*}{ TCFA } & 0,25 & 28 & 18 & 24 & 36 \\
65/35-FS & 0,38 & 36 & 20 & 24 & 36 \\
& 0,52 & 36 & 24 & 24 & 36 \\
\hline \multirow{2}{*}{ TCFA } & 0,23 & 36 & 24 & 24 & 36 \\
80/60-FCP & 0,36 & 38 & 28 & 24 & 36 \\
& 0,50 & 39 & 30 & 24 & 36 \\
\hline \multirow{2}{*}{ TCFA } & 0,25 & 40 & 30 & 24 & 36 \\
80/60-FS & 0,38 & 40 & 34 & 24 & 36 \\
& 0,52 & 42 & 37,5 & 24 & 36 \\
\hline
\end{tabular}

\section{Nota: Legenda:}

CMF - carga máxima de fissura;

CMPF - carga máxima pós-fissuração;

$\mathrm{CmF}$ - carga mínima de fissura;

CID - carga isenta de dano; e

$\mathrm{CmR}$ - carga mínima de ruptura.

A fim de melhor visualizar a influência do teor efetivo de fibras no comportamento mecânico dos tubos, houve a elaboração das Figuras 13 e 14, que mostram uma tendência de aumento da carga de ruptura e máxima pós-fissuração para maiores níveis de teores efetivos de fibras. Observa-se que em todos os teores efetivos analisados os tubos de concreto das séries TCFA - 80/60 - FCP e TCFA 80/60 - FS apresentaram melhores resultados de carga de ruptura e máxima pós-fissuração em relação aos tubos de concreto das séries TCFA 65/35 - FCP e TCFA - 65/35 - FS. Esse comportamento foi observado por Escariz (2012) e Mohamed (2015). As fibras do tipo 65/35, denominadas como fibras curtas, deslizam quando atuam como ponte de transferência de tensões, exercendo menor parcela de contribuição (MOHAN; PARTHIBAN, 2011).

Os tubos de concreto das séries TCFA - 80/60 - FS e TCFA - 65/35 - FS, quando analisados entre si o mesmo teor de fibras, apresentaram maiores cargas de ruptura e máxima pós-fissuração em relação aos tubos de concreto das séries TCFA - 80/60 - FCP e
TCFA - 65/35 - FCP. Ao final houve melhor desempenho dos tubos de concreto da série TCFA - 80/60 - FS.

A análise dos deslocamentos verticais diametrais ocorreu a partir dos resultados de cargas obtidas no deslocamento vertical diametral de $8 \mathrm{~mm}$ atingidas pelos tubos de concreto de armadura contínua convencional de série TCA e de armadura descontínua com fibras de aço de série TCFA $80 / 60$ - FS nos teores efetivos de $0,25 \%, 0,38 \%$ e $0,52 \%$, de série TCFA - 80/60 - FCP no teor efetivo de $0,50 \%$, e de série TCFA - 65/35 - FS nos teores efetivos de $0,38 \%$ e $0,52 \%$, conforme apresenta a Tabela 11 .

O deslocamento vertical diametral de $8 \mathrm{~mm}$ foi adotado, visto que a instabilidade pós-pico e o recarregamento haviam ocorrido, e a fim de verificar o comportamento pós-fissuração dos tubos de concreto da série TCA e dos tubos de concreto da série TCFA, que foram submetidos a ensaio de carregamento contínuo e cíclico, respectivamente. 
Figura 13- Carga de ruptura dos tubos de concreto da série TCFA versus teor efetivo de fibras coladas em pente e soltas do tipo 65/35 e 80/60

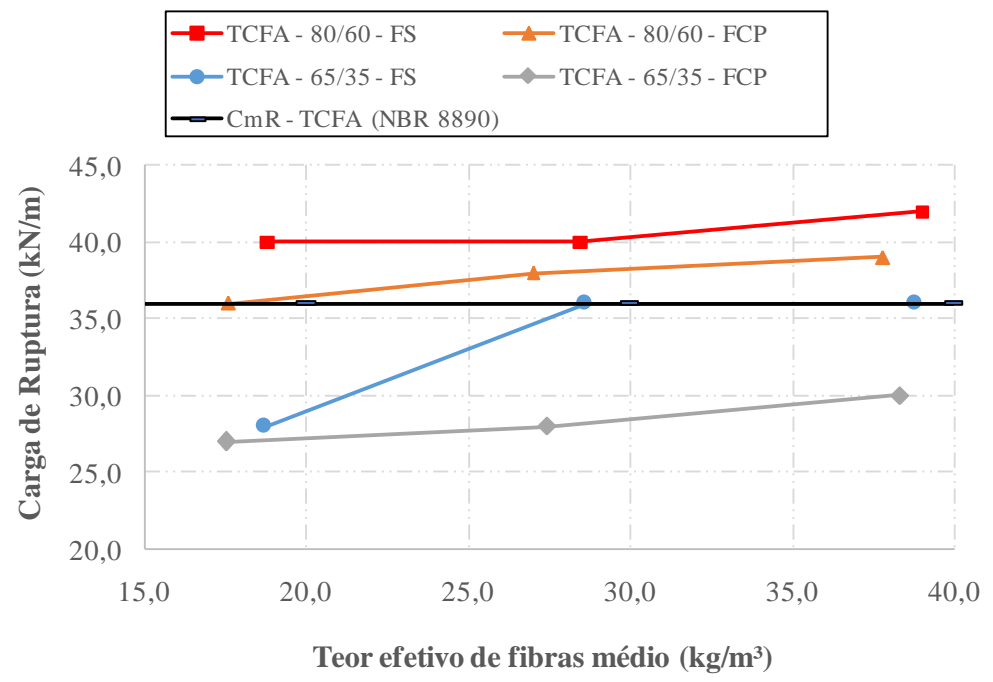

Figura 14 - Carga máxima pós-fissuração dos tubos de concreto da série TCFA versus teor efetivo de fibras coladas em pente e soltas do tipo $65 / 35$ e $80 / 60$

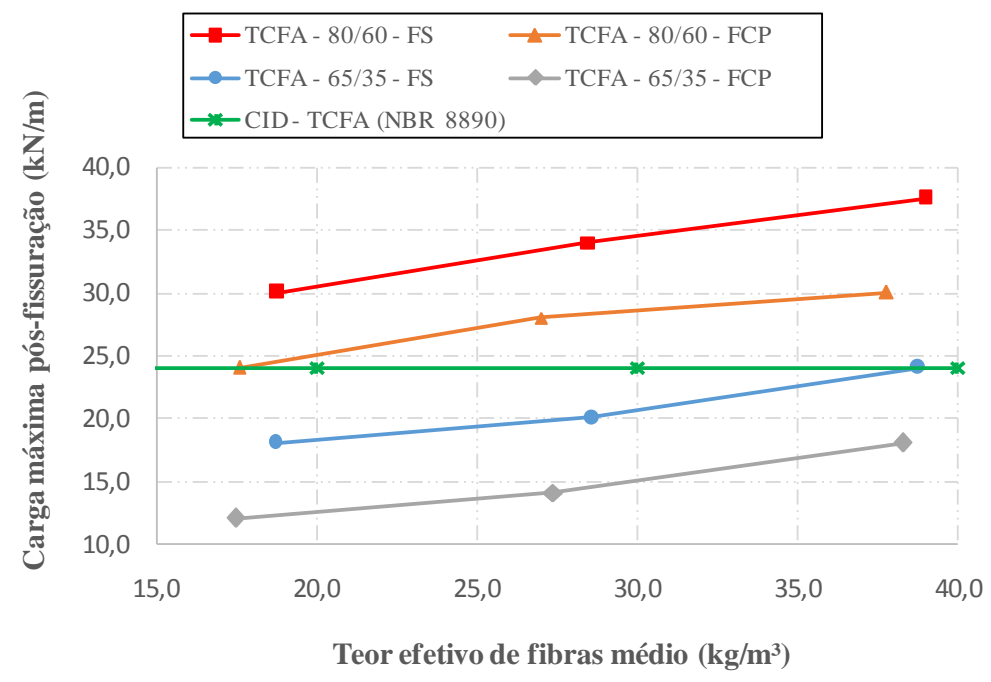

Tabela 11 - Resultados de carregamento contínuo e cíclico para deslocamento em $18 \mathrm{~mm}$

\begin{tabular}{l|c|c}
\hline \multirow{2}{*}{ Série } & \multicolumn{2}{c}{$\begin{array}{c}\text { Carga em kN, obtida no deslocamento vertical } \\
\text { diametral de } \mathbf{8} \mathbf{~ m m}\end{array}$} \\
\cline { 2 - 3 } & $\begin{array}{c}\text { Ensaio com } \\
\text { carregamento contínuo }\end{array}$ & $\begin{array}{c}\text { Ensaio com } \\
\text { carregamento cíclico }\end{array}$ \\
\hline TCA - médio & 37,0 & 8,0 \\
TCFA 65/35 0,38\% FS & - & 21,0 \\
TCFA 65/35 - 0,52\% FS & - & 24,0 \\
TCFA 80/60 0,36\% FCP & - & 30,0 \\
TCFA 80/60 0,50\% FCP & - & 26,0 \\
TCFA 80/60 0,25\% FS & - & 30,0 \\
TCFA 80/60 0,38\% FS & - & 32,0 \\
TCFA 80/60 0,52\% FS & - & \\
TCA - médio & 37,0 & \\
\hline
\end{tabular}


Na Figura 15 observa-se que na medida em que foi percebido o aumento do teor efetivo de fibras houve maiores níveis de carga no deslocamento de $8 \mathrm{~mm}$ dos tubos de concreto da série TCFA. A carga no deslocamento de $8 \mathrm{~mm}$ apresentou melhores resultados a partir da ordem: série TCA, TCFA - 80/60 - FS, TCFA - 80/60 - FCP e TCFA $65 / 35$ - FS.

O resultado da carga no deslocamento vertical diametral de $8 \mathrm{~mm}$ foi obtido a partir das curvas de carga versus deslocamento dos tubos de concreto da série TCA e da série TCFA - 65/35 - FS nos teores efetivos de $0,38 \%$ e $0,52 \%$, da série TCFA $80 / 60$ - FCP, nos teores efetivos de 0,36\% e $0,50 \%$, e da série TCFA - 80/60 - FS nos teores efetivos de $0,25 \%, 0,38 \%$ e $0,52 \%$, conforme mostram as Figuras 16, 17 e 18. E pode-se notar que os tubos de concreto da série TCA e TCFA, respectivamente, apresentaram um comportamento strain-hardening e strain-softening. Os tubos de concreto da série TCFA 80/60 - FS nos teores efetivos de $0,38 \%$ e $0,52 \%$ suportaram maiores níveis de deslocamento vertical diametral e abertura de fissura.

\section{Absorção de água}

Entre os tubos de concreto de referência, de armadura contínua convencional e descontínua com fibras de aço obteve-se maior absorção média de água de 5,50\%, conforme Tabela 12 , portanto inferior a $8 \%$, conforme recomendação da NBR 8890 (ABNT, 2007) para tubos de concreto destinados a águas pluviais.

Figura 15 - Carga no deslocamento vertical diametral de $18 \mathrm{~mm}$ para carregamento contínuo e cíclico

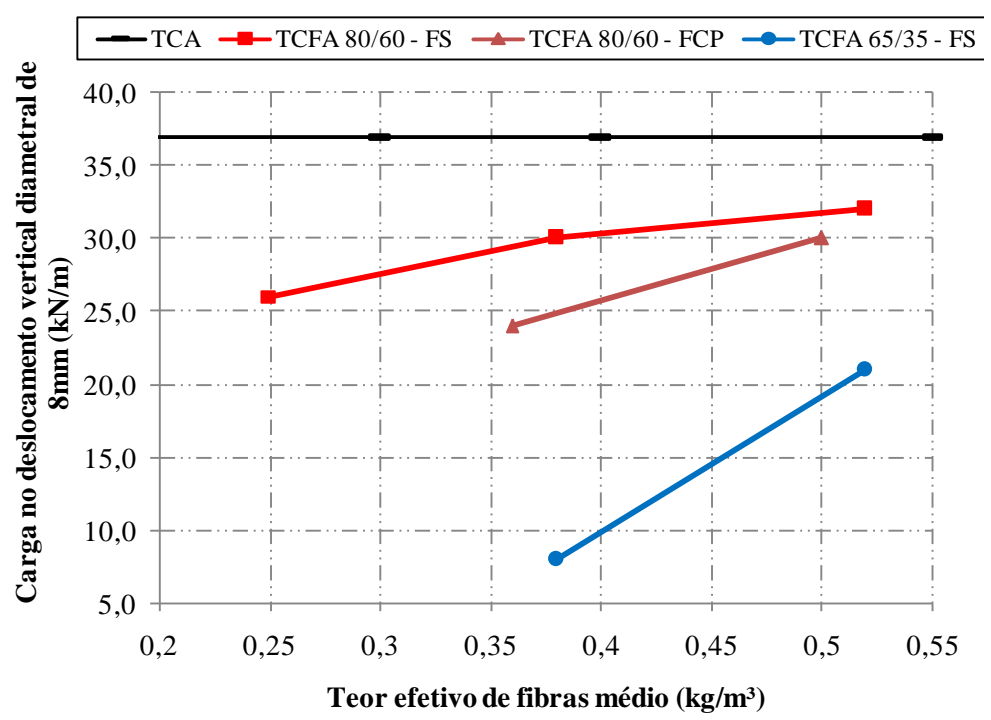

Figura 16 - Curvas de carga versus deslocamento vertical diametral da série TCA e TCFA 65/35 FS

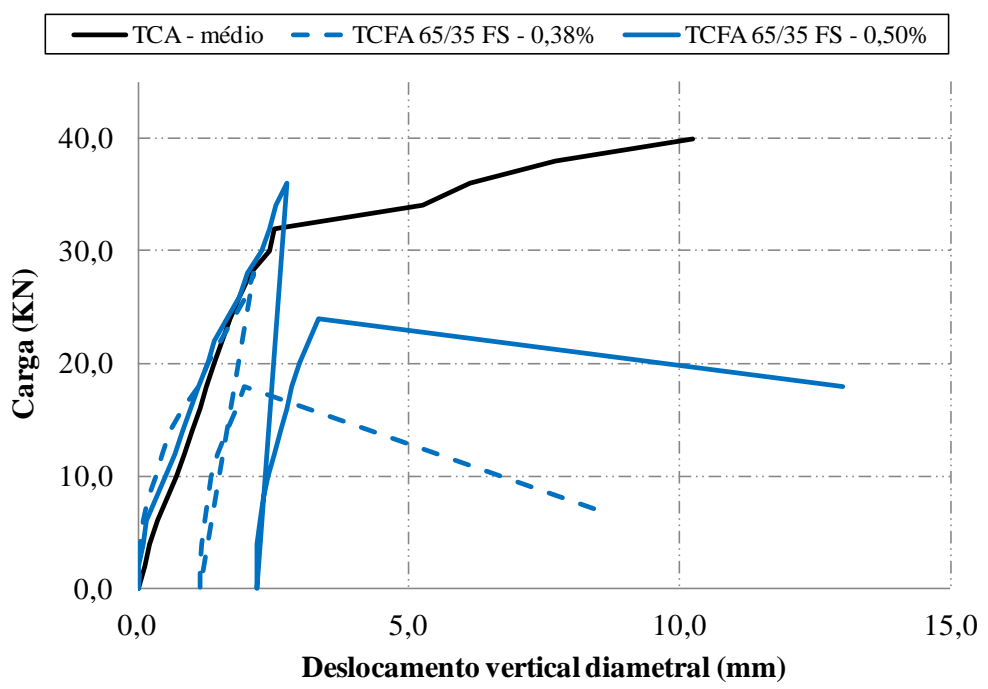

154 Oliveira, M. A. B. de; Macêdo, A. N.; Pompeu, B. B. Cabral, A. E. B. 
Figura 17 - Curvas de carga versus deslocamento vertical diametral da série TCA e TCFA 80/60 FCP

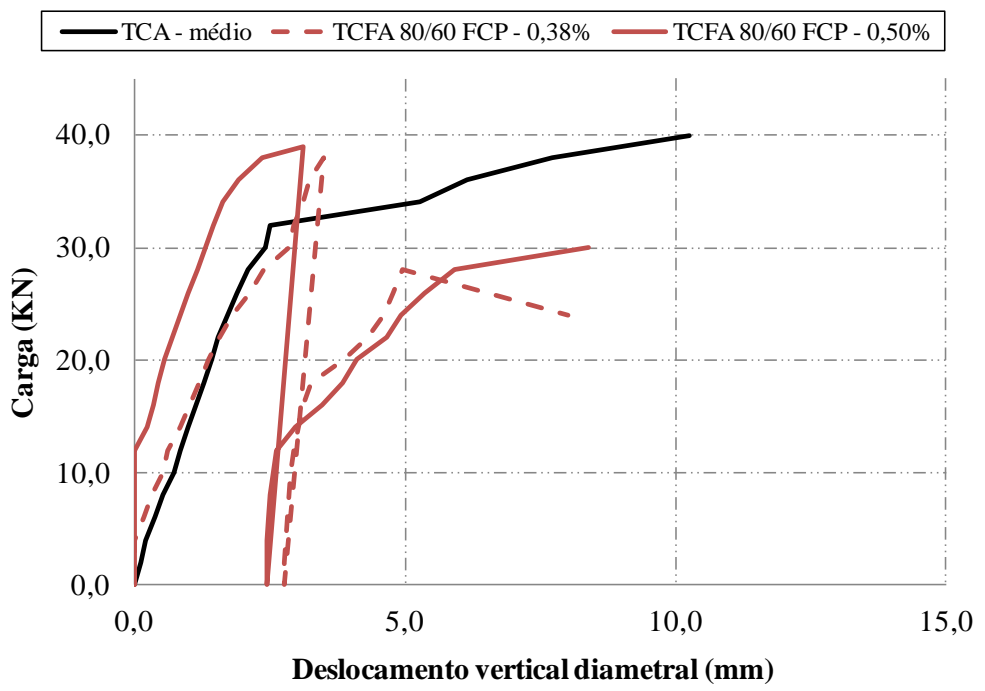

Figura 18 - Curvas de carga versus deslocamento vertical diametral da série TCA e TCFA 80/60 FS

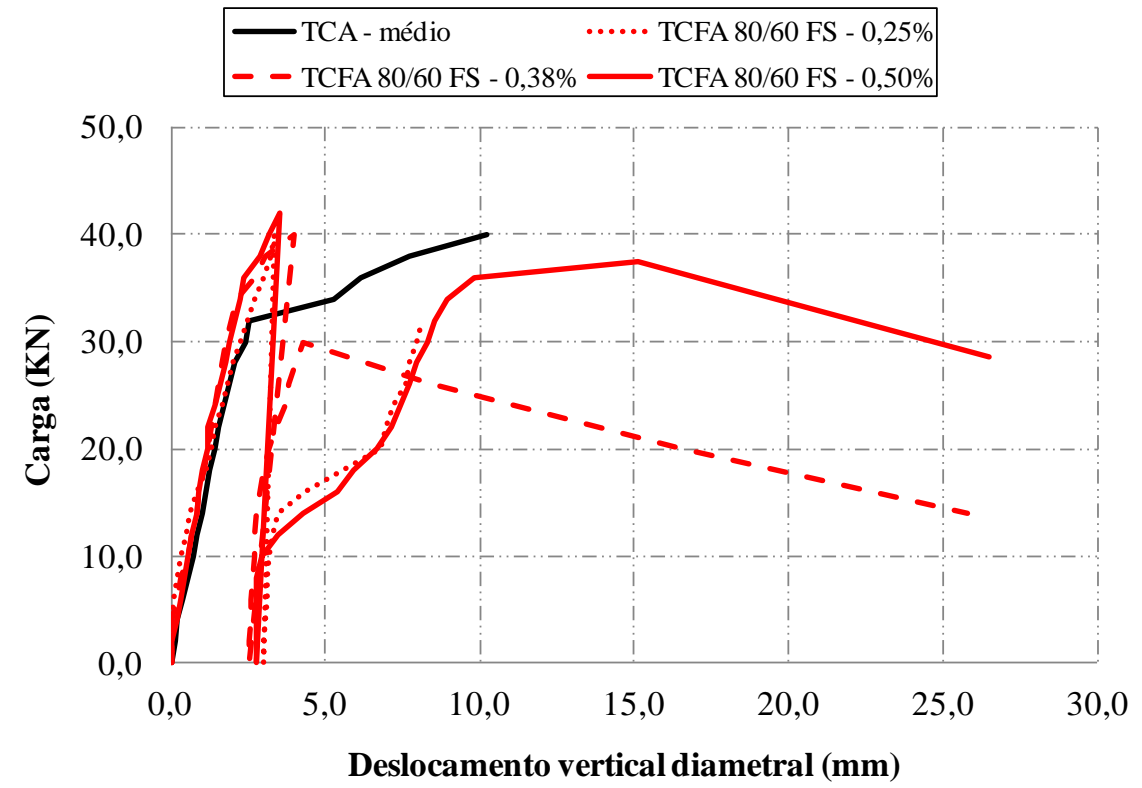

Tabela 12 - Resultados de absorção média na região da ponta, meio e bolsa do tubo

\begin{tabular}{|c|c|c|c|c|c|}
\hline \multirow{2}{*}{ Série } & \multirow{2}{*}{$t_{e f f, i}$} & \multirow[b]{2}{*}{$\chi_{, i}$} & \multicolumn{3}{|c|}{ Absorção média (\%) } \\
\hline & & & Ponta & Meio & Bolsa \\
\hline \multirow{3}{*}{ TCFA 65/35-FCP } & $t_{\text {eff }, 1}$ & $\overline{\chi_{1}}$ & 3,7 & 3,8 & 4,9 \\
\hline & $t_{\text {eff }, 2}$ & $\chi_{2}$ & 2,9 & 3,3 & 4,3 \\
\hline & $t_{e f f, i 3}$ & $\chi 3$ & 3,5 & 3,8 & 4,1 \\
\hline \multirow{3}{*}{ TCFA $65 / 35-F S$} & $t_{e f f, 4}$ & $\chi_{4}$ & 4,2 & 4,3 & 5,0 \\
\hline & $t_{e f f, 5}$ & $\chi, 5$ & 3,4 & 3,7 & 3,9 \\
\hline & $t_{\text {eff, },}$ & $\chi_{6}$ & 3,4 & 4,1 & 4,5 \\
\hline \multirow{3}{*}{ TCFA 80/60-FCP } & $t_{\text {eff }, 7}$ & $\chi_{07}$ & 4,1 & 5,3 & 5,5 \\
\hline & $t_{\text {eff }, 8}$ & $\chi_{8}$ & 2,9 & 3,3 & 4,1 \\
\hline & $t_{e f f, 9}$ & $\chi 9$ & 2,8 & 3,5 & 4,7 \\
\hline \multirow{3}{*}{ TCFA 80/60-FS } & $t_{e f f, 10}$ & $\chi_{110}$ & 3,7 & 4,3 & 4,3 \\
\hline & $t_{e f f, 11}$ & $\chi_{11}$ & 3,9 & 4,0 & 4,4 \\
\hline & $t_{e f f, 12}$ & $\chi_{, 12}$ & 4,4 & 4,6 & 4,9 \\
\hline
\end{tabular}


A Tabela 12 apresenta a absorção média $\left(\chi_{, i}\right)$ das amostras dos tubos na região da ponta, meio e bolsa correspondente a cada teor efetivo final de fibras $\left(t_{\text {eff }, i}\right)$. Notou-se que para cada teor efetivo final de fibras $\left(t_{\text {eff, } i}\right)$ houve aumento da absorção média $(\chi, i)$ na cadeia ponta, meio e bolsa, conforme mostra a Figura 19. Isso pode ter ocorrido pela fato de a vibração do equipamento não proporcionar adensamento homogêneo.

Observou-se boa aderência da regressão para linha de tendência exponencial, quando correlacionadas a absorção média $\left(\chi_{, i}\right)$ com seus respectivos teores de efetivos de fibras médios $\left(t_{e f, i}\right)$ obtidos na região da ponta, meio e bolsa do tubo, indicando maiores níveis de absorção com aumento do teor efetivo de fibras. Obteve-se boa correlação para os tubos de concreto da série TCFA - 80/60, em que apresenta coeficiente de determinação da regressão $\mathrm{R}^{2}$ (mínimo de 0,90) com melhor aderência para a linha de tendência com função exponencial, conforme mostram as Figuras 20 a 23.

Figura 19 - Absorção média da região da ponta, meio e bolsa para cada teor efetivo final

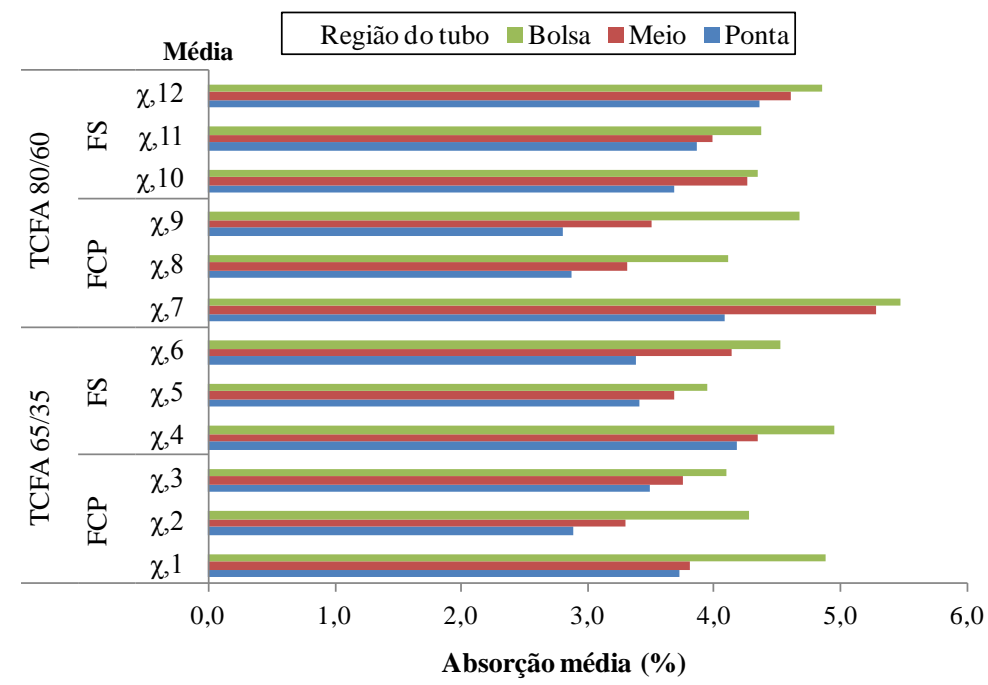

Figura 20 - Correlação da absorção média e respectivos teores efetivos da ponta, meio e bolsa da série TCFA - 65/35 - FCP

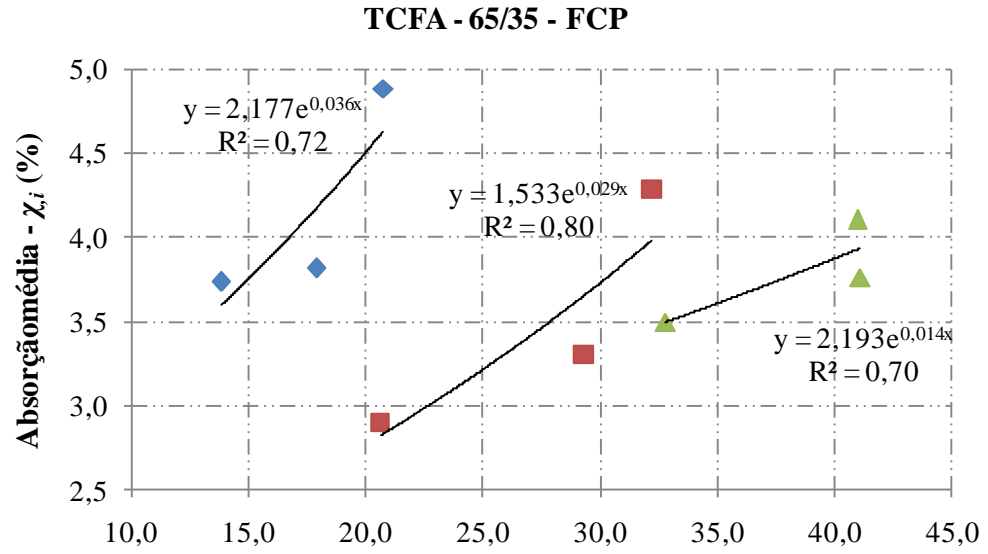

Teor efetivo de fibras médio $-t_{e f, i}\left(\mathrm{~kg} / \mathrm{m}^{3}\right)$

Média $\bullet, 1 \square, 2 \Delta \chi, 3$ 
Figura 21 - Correlação da absorção média e respectivos teores efetivos da ponta, meio e bolsa da série TCFA - 65/35 - FS

\section{TCFA - 65/35 - FS}

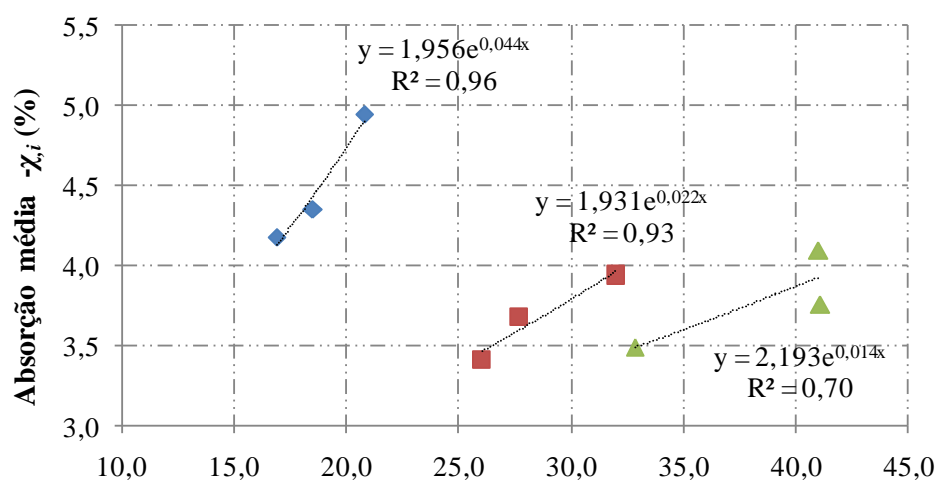

Teor efetivo de fibras médio $-t_{e f, i}\left(\mathrm{~kg} / \mathrm{m}^{3}\right)$

Média $\bullet 4 \square \chi 5 \Delta \chi 6$

Figura 22 - Correlação da absorção média e respectivos teores efetivos da ponta, meio e bolsa da série TCFA - 80/60 - FCP

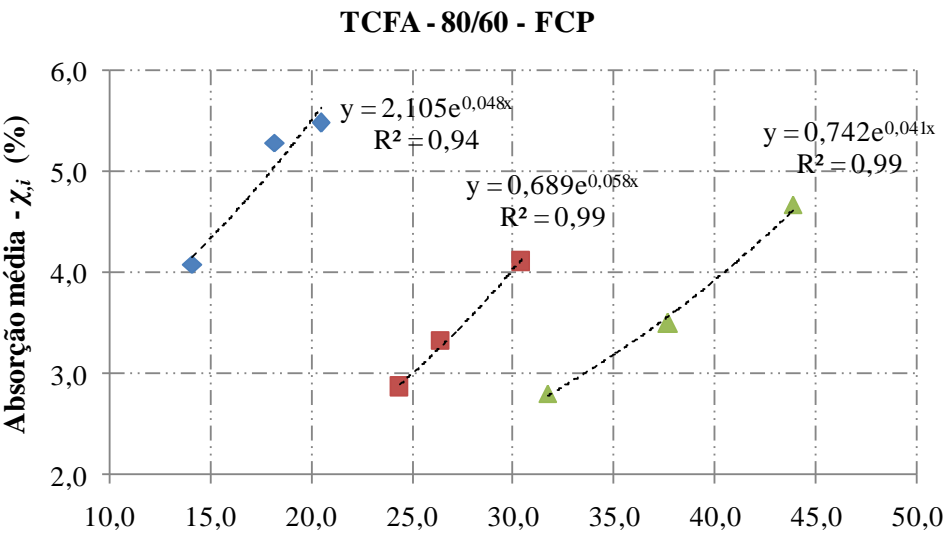

Teor efetivo de fibras médio $-t_{e f, i}\left(\mathbf{k g} / \mathbf{m}^{3}\right)$

Média $\bullet, 7 \nabla \chi, 8 \triangle \chi, 9$

Figura 23 - Correlação da absorção média e respectivos teores efetivos da ponta, meio e bolsa da série TCFA - 80/60 - FS

TCFA - 80/60 - FS

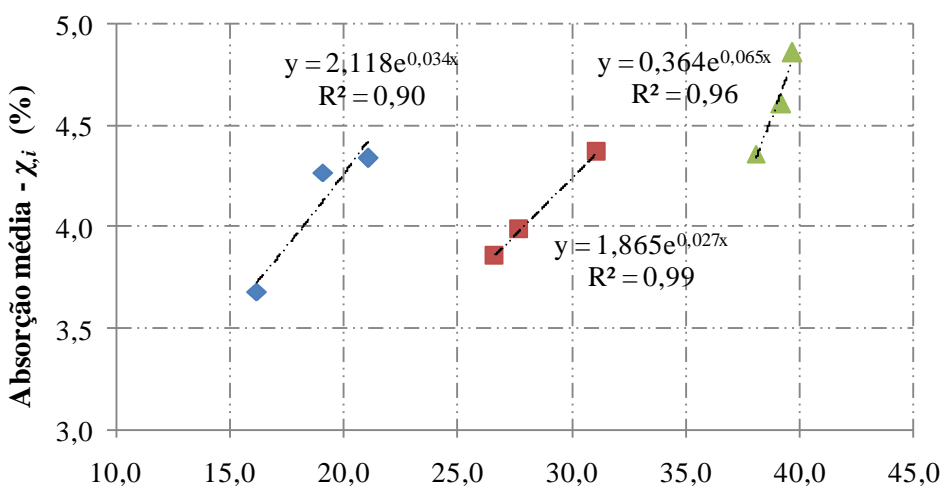

Teor efetivo de fibras médio $-t_{e f, i}\left(\mathrm{~kg} / \mathrm{m}^{3}\right)$

Média $\bullet, 10 \square \chi 11 \Delta \chi 12$ 
$\mathrm{Na}$ avaliação da dispersão dos resultados individuais de absorção de água dos tubos de concreto da série TCS, TCA e TCFA, observaramse mais acentuada a variabilidade em relação à tendência central e maiores amplitudes das amostras das séries TCFA - FCP, conforme mostra a Figura 24.

A Figura 25 apresenta para cada série TCFA a absorção média da amostra de cada faixa $\left(\chi_{f, i}\right)$ e absorção média final da faixa $\left(\chi f f_{, i}\right)$ do seu respectivo teor efetivo final de fibras médio $\left(t_{e f f, i}\right)$.

Figura 24 - Dispersão dos resultados individuais de absorção de água

\begin{tabular}{|c|c|c|c|c|}
\hline \multirow{2}{*}{ Série } & \multirow{2}{*}{$t_{e f f, i}$} & \multirow{2}{*}{ Faixa } & \multicolumn{2}{|c|}{ Absorção média (\%) } \\
\hline & & & $\chi f_{, i}$ & $\chi f f_{, i}$ \\
\hline \multirow{3}{*}{ TCFA 65/35-FCP } & $t_{e f f, 1}$ & $\begin{array}{l}\text { FA } \\
\text { FB }\end{array}$ & $\begin{array}{l}\chi_{f, A} \\
\chi_{f, B}\end{array}$ & 3,5 \\
\hline & $t_{e f f, i 2}$ & $\begin{array}{l}\text { FC } \\
\text { FD }\end{array}$ & $\begin{array}{l}\chi_{f, C} \\
\chi_{f, D}\end{array}$ & 3,8 \\
\hline & $t_{e f f, 3}$ & $\begin{array}{l}\text { FE } \\
\text { FF }\end{array}$ & $\begin{array}{l}\chi_{f, E} \\
\chi_{f, F}\end{array}$ & 4,1 \\
\hline \multirow{3}{*}{ TCFA 65/35-FS } & $t_{e f f, 4}$ & $\begin{array}{l}\text { FG } \\
\text { FH }\end{array}$ & $\begin{array}{l}\chi_{f, G} \\
\chi_{f, H}\end{array}$ & 3,7 \\
\hline & $t_{\text {eff }, 5}$ & $\begin{array}{l}\text { FI } \\
\text { FJ }\end{array}$ & $\begin{array}{l}\chi_{f, I} \\
\chi_{f, J}\end{array}$ & 4,0 \\
\hline & $t_{e f f, 6}$ & $\begin{array}{l}\text { FK } \\
\text { FL }\end{array}$ & $\begin{array}{l}\chi_{f, K} \\
\chi_{f, L}\end{array}$ & 4,5 \\
\hline \multirow{3}{*}{ TCFA 80/60-FCP } & $t_{e f f, 7}$ & $\begin{array}{l}\text { FM } \\
\text { FN }\end{array}$ & $\begin{array}{l}\chi_{f, M} \\
\chi_{f, N}\end{array}$ & 3,4 \\
\hline & $t_{\text {eff }, i 8}$ & $\begin{array}{l}\text { FO } \\
\text { FP }\end{array}$ & $\begin{array}{l}\chi_{f, O} \\
\chi_{f, P}\end{array}$ & 3,7 \\
\hline & $t_{e f f, 9}$ & $\begin{array}{l}\text { FQ } \\
\text { FR }\end{array}$ & $\begin{array}{l}\chi_{f, Q} \\
\chi_{f, R}\end{array}$ & 5,0 \\
\hline \multirow{3}{*}{ TCFA 80/60-FS } & $t_{\text {eff, }, 10}$ & $\begin{array}{l}\text { FS } \\
\text { FT }\end{array}$ & $\begin{array}{l}\chi_{f, S} \\
\chi_{f, T}\end{array}$ & 4,1 \\
\hline & $t_{e f f, 11}$ & $\begin{array}{l}\text { FU } \\
\text { FV }\end{array}$ & $\begin{array}{l}\chi_{f, U} \\
\chi_{f, V}\end{array}$ & 4,1 \\
\hline & $t_{e f f, 12}$ & $\begin{array}{l}\text { FW } \\
\text { FX }\end{array}$ & $\begin{array}{l}\chi_{f, W} \\
\chi_{f, X}\end{array}$ & 4,7 \\
\hline
\end{tabular}

Figura 25 - Resultados de absorção média das faixas dos tubos

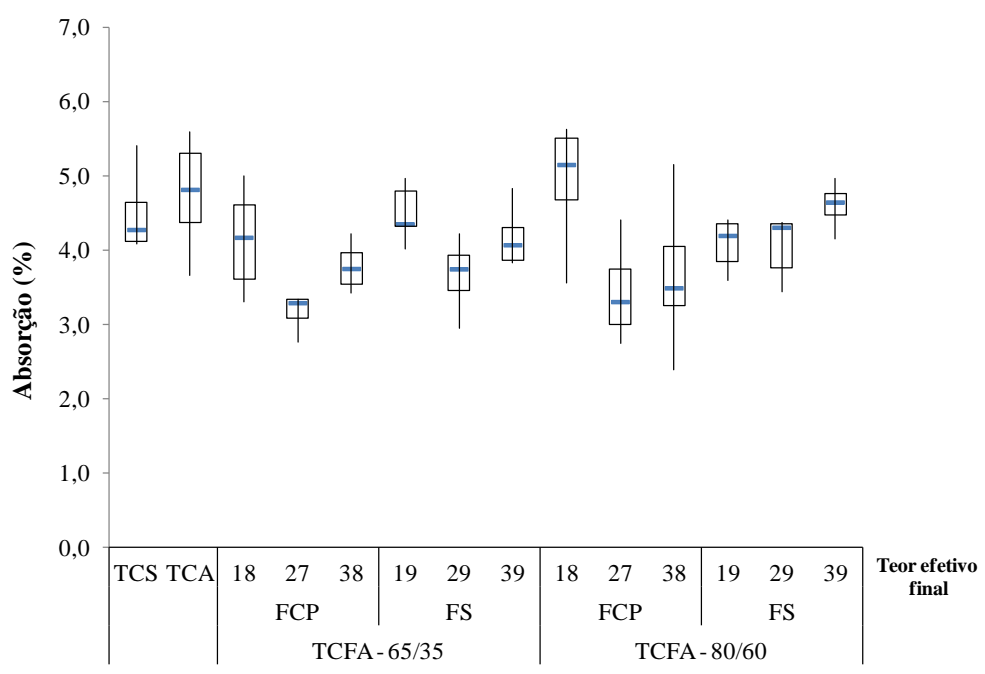

158 Oliveira, M. A. B. de; Macêdo, A. N.; Pompeu, B. B. Cabral, A. E. B. 
As Figuras 26 e 27 mostram correlações entre a absorção média final da faixa ( $\chi \mathrm{ff}, \mathrm{i})$ e seu respectivo teor efetivo final médio (teff,i). Verifica-se para todas as séries TCFA que à medida que aumenta o teor efetivo final há uma tendência de crescimento da absorção média final da faixa, com boa correlação (mínimo de 0,90) do coeficiente de determinação $\mathrm{R}^{\mathbf{2}}$ para regressão com linha de tendência com melhor aderência para a função exponencial.

\section{Verificação do teor efetivo de fibras}

Ao analisar o teor efetivo de fibras incorporadas aos tubos de concreto da série TCFA, verificou-se que houve aumento do teor efetivo médio de fibras na cadeia de ordem da região da ponta, meio e bolsa do tubo, conforme a Figura 28, o que pode explicar maiores níveis de absorção de água ocorrida de modo semelhante no encadeamento ponta, meio e bolsa. Isso pode ser explicado pela dificuldade de compactação homogênea pelo equipamento utilizado na pesquisa.

Observou-se que houve proximidade entre os resultados de teores efetivos finais e teores teóricos, conforme mostra a Figura 29, com obtenção de forte correlação do coeficiente de determinação $\mathrm{R}^{2}$ (mínimo de 0,99 ) com satisfatória aderência da regressão na função potencial.

Figura 26 - Correlação da absorção média final da faixa e respectivo teor efetivo final da faixa da série TCFA - $65 / 35$

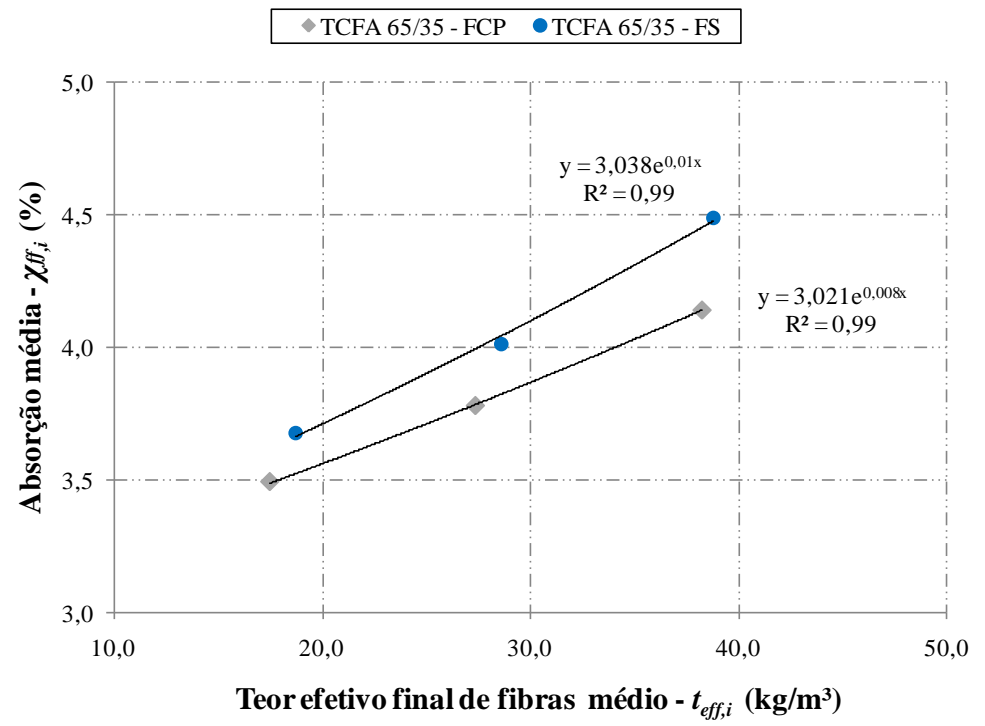

Figura 27 - Correlação da absorção média final da faixa e respectivo teor efetivo final da faixa da série TCFA - $80 / 60$

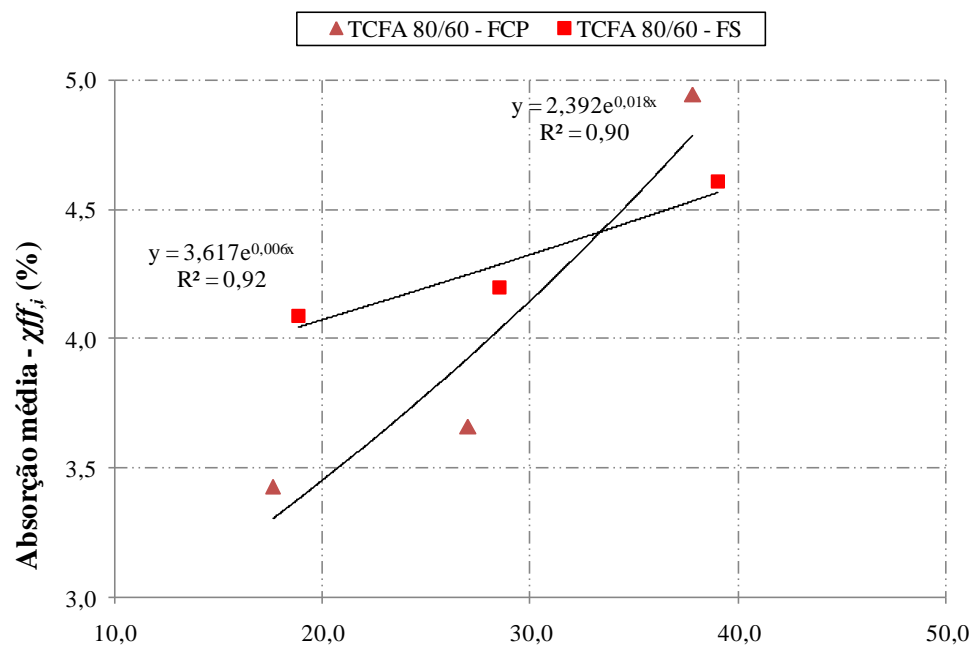

Teor efetivo final de fibras médio- $t_{e f f, i}\left(\mathrm{~kg} / \mathrm{m}^{3}\right)$ 
Figura 28 - Teor efetivo de fibras médio da região da ponta, meio e bolsa do tubo

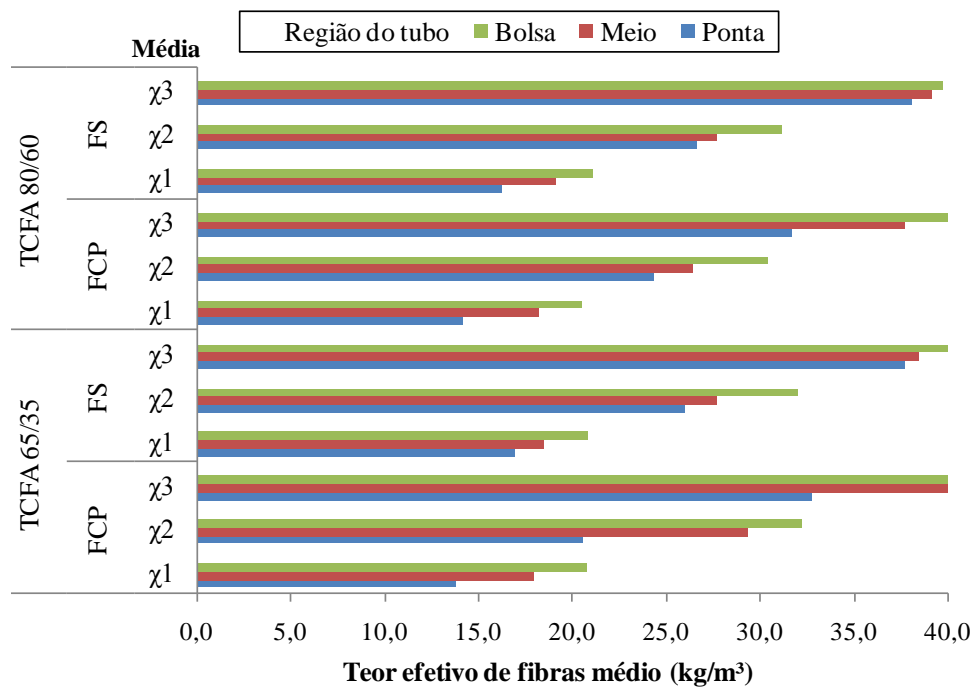

Figura 29 - Correlação entre o teor efetivo médio e teor teórico adotado

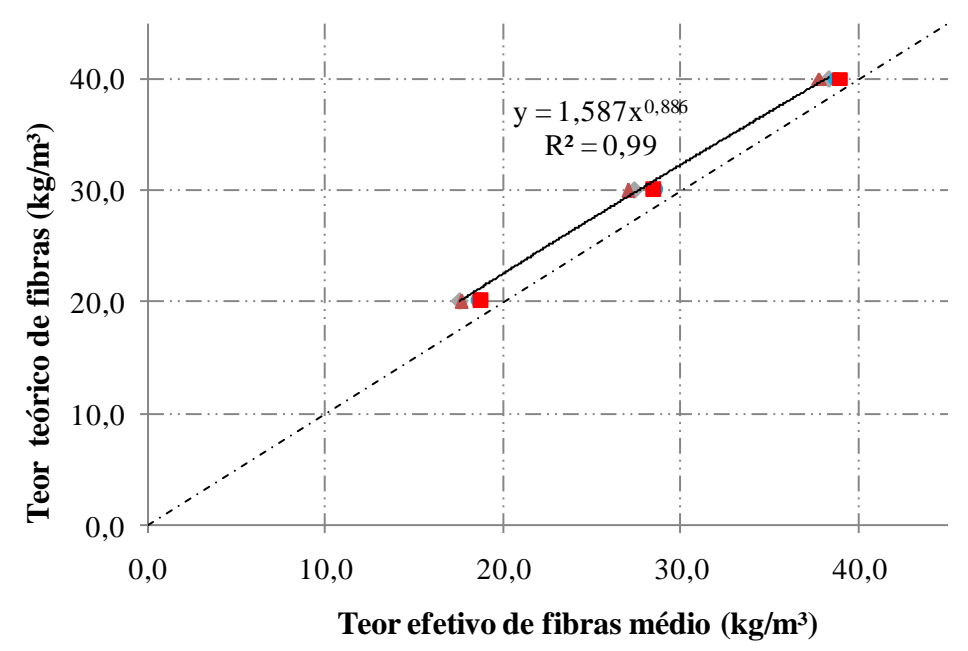

$\mathrm{Na}$ avaliação da dispersão dos resultados individuais de teores efetivos de fibras incorporada nos tubos de concreto, notou-se que houve variabilidade em relação à tendência central para todas as séries, e maiores amplitudes para as séries TCFA - FCP, conforme mostra a Figura 30.

\section{Conclusões}

$\mathrm{Na}$ análise dos resultados obtidos, considerando as condições adotadas neste estudo, entre elas tipos de equipamentos para a produção dos tubos de concreto, das especificações dos tubos de concreto, dos tipos de fibras de aço, dos teores de fibras e dosagem do concreto e das fibras utilizados, podese concluir:

A reologia do concreto seco utilizado para produção de tubo de concreto apresenta-se mais consistente e coesa, a fim de garantir a estabilidade dimensional do componente desformado logo após a moldagem (FIGUEIREDO; TANESI; NINCE, 2002). A adição das fibras de aço influenciou na consistência e coesão da mistura. A perda de mobilidade da mistura foi influenciada pelo comprimento da fibra acima do dobro do diâmetro máximo do agregado.

Na produção dos tubos de concreto da série TCFA adotou-se a dosagem e relação água/cimento rotineiramente empregada na fabricação de tubos de concreto da série TCS e TCA, sem a utilização de aditivos, que refletiu na redução da fluidez da mistura. Desse modo, tais fatores influenciaram na diminuição da trabalhabilidade, sendo mais pronunciada nos tubos de concreto da série TCFA $80 / 60$ no teor de fibras de $0,50 \%$, sem onerar, no entanto, o processo de mistura e moldagem dos tubos. 
Figura 30 - Dispersão dos resultados individuais de teor efetivo de fibras

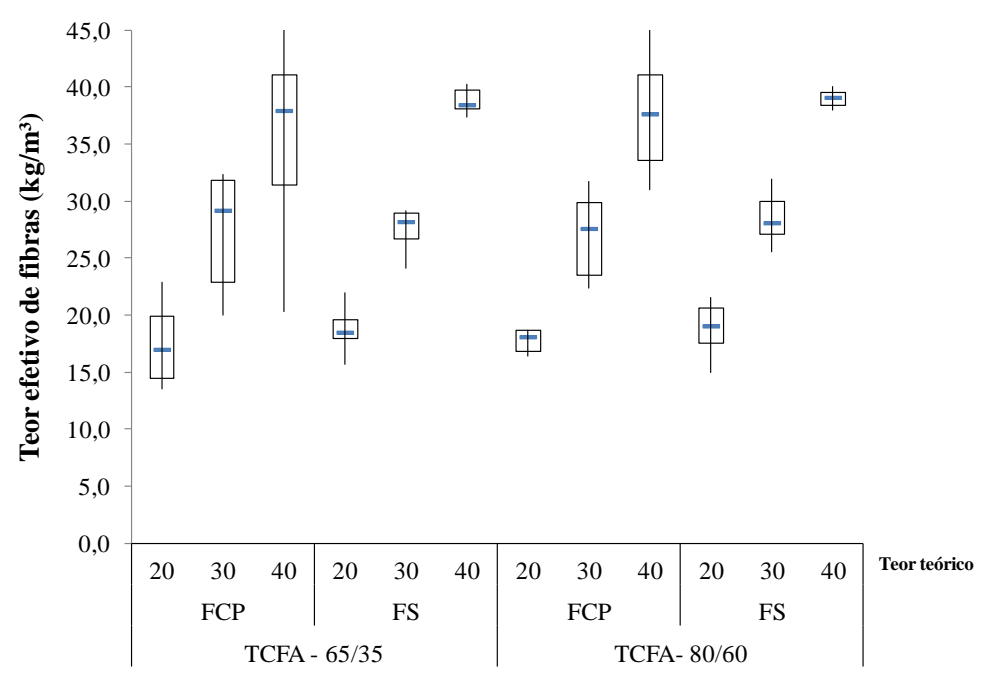

Em análise da absorção de água obteve-se valores abaixo do recomendado pela NBR 8890 (ABNT, 2007) para os tubos de concreto das séries TCS, TCA e TCFA com destinação para as águas pluviais. Verificou-se que houve aumento da absorção média na cadeia de ordem da ponta, meio e bolsa do tubo para seus respectivos teores efetivos de fibras.

De modo similar houve aumento da absorção média das faixas do tubo para seus respectivos teores efetivos finais médios. Ambos obtiveram boa correlação de coeficiente de determinação $\mathrm{R}^{2}$ (mínimo de 0,90). A dispersão dos resultados de absorção de água apontou uma variabilidade e amplitude mais acentuada para as amostras das séries TCFA 80/60 - FCP.

$\mathrm{Na}$ análise do teor efetivo de fibras observou-se aumento do teor efetivo médio de fibras na cadeia de ordem da região da ponta, meio e bolsa do tubo, o que corroborou no comportamento semelhante da absorção de água com aumento na sucessão da ponta, meio e bolsa. Dessa maneira, maiores teores efetivos de fibras podem influenciar em maiores níveis de absorção de água por apresentar maior grau de porosidade.

De modo geral houve satisfatória incorporação das fibras, pois se obteve valores de teor efetivo final próximo do teor teórico adotado com intensa correlação do coeficiente de determinação $\mathrm{R}^{2}$ (acima de 0,99). No entanto, a média do teor efetivo final de fibras em relação ao teor teórico adotado foi menor na série TCFA - FCP em comparação à série TCFA - FS, ou seja, houve menor incorporação das fibras coladas em pente nos tubos de concreto. Isso pode ter ocorrido pela dificuldade de descolagem das fibras coladas em pente no processo. Desse modo, possíveis perdas influenciaram de maneira mais significativa no teor efetivo de fibras da série TCFA - FCP. A análise de dispersão dos resultados de teores efetivos indicou maior variabilidade e amplitude para a série TCFA 80/60 - FCP.

O comportamento apresentado na absorção de água e teor efetivo de fibras pode ser explicado pela menor energia de compactação do tipo de equipamento utilizado no estudo, que não proporcionou uma distribuição uniforme do teor de fibras com surgimento de aglomeração de fibras em dois tubos de concreto da série TCFA 80/60 no teor de $0,50 \%$. No entanto, houve um nível de energia apropriado de compactação que assegurou um bom acabamento superficial sem fibras aparentes na superfície do tubo.

Ainda que os resultados de reologia, absorção e teor efetivo de fibras tenham sido influenciados com mais representatividade pela série TCFA $80 / 60$, observou-se que os tubos de concreto das séries de TCFA - 80/60 - FCP e TCFA - 80/60 FS apresentaram melhores resultados de cargas de ruptura e máximas pós-fissuração em relação aos tubos de concreto das séries de TCFA - 65/35 FCP e TCFA - 65/35 - FS.

É provável que a esbeltez da parede do tubo e o comprimento da fibra do tipo 80/60, que está próximo da dimensão da espessura da parede do tubo, tenham provocado um alinhamento diametral das fibras do tipo 80/60 com orientação preferencial aos planos longitudinais de fissuração e de tensões principais atuantes no tubo. Isso pode ter contribuído para maiores níveis de resistência da série TCFA 80/60.

Os tubos de concreto das séries TCFA - 80/60 - FS e TCFA - 65/35 - FS obtiveram melhores desempenhos de comportamento mecânico em 
comparação aos tubos de concreto das séries TCFA - 80/60 - FCP e TCFA - 65/35 - FCP. Isso pode ser explicado por ter havido maiores níveis de teores efetivos de fibras incorporadas da forma FS (fibras soltas).

\section{Referências}

ASKELAND, D. R.; WRIGTH, W. J. Ciência e Engenharia dos Materiais. Cecange Learning, 2014.

ASSOCIAÇÃO BRASILEIRA DE NORMAS

TÉCNICAS. NBR 11578: cimento Portland composto. Rio de Janeiro, 1997.

ASSOCIAÇÃO BRASILEIRA DE NORMAS TÉCNICAS. NBR 7211: agregados para concreto: especificação. Rio de Janeiro, 2009c.

ASSOCIAÇÃO BRASILEIRA DE NORMAS

TÉCNICAS. NBR 8890: tubo de concreto de seção circular para águas pluviais e esgotos sanitários: requisitos e métodos de ensaios. Rio de Janeiro, 2007.

ASSOCIAÇÃO BRASILEIRA DE NORMAS TÉCNICAS. NBR NM 23: cimento Portland e outros materiais em pó: determinação de massa esepcífica. Rio de Janeiro, 2001.

ASSOCIAÇÃO BRASILEIRA DE NORMAS TÉCNICAS. NBR NM 248: determinação da composição granulométrica. Rio de Janeiro, 2003.

ASSOCIAÇÃO BRASILEIRA DE NORMAS TÉCNICAS. NBR NM 45: agregados:

determinação da massa unitária e do volume de vazios. Rio de Janeiro, 2006.

ASSOCIAÇÃO BRASILEIRA DE NORMAS

TÉCNICAS. NBR NM 52: agregado miúdo: determinação de massa específica e massa específica aparente. Rio de Janeiro, 2009a.

ASSOCIAÇÃO BRASILEIRA DE NORMAS TÉCNICAS. NBR NM 53: agregado graúdo: determinação de massa específica, massa específica aparente e absorção de água. Rio de Janeiro, 2009b.

ASSOCIAÇÃO BRASILEIRA DE NORMAS TÉCNICAS. NBR NM 67: determinação da consistência pelo abatimento do tronco de cone. Rio de Janeiro, 1998.

DE LAFUENTE, A.et al. Experimentación y Simulación Numérica de Tubos de Hormigón Com Fibras. Materiales de Construccion, v. 61, p. 275-288, 2011.
ESCARIZ, R. C. Análise Comparativa de Desempenho Mecânico De Tubos de Concreto Reforçados Com Macrofibras Poliméricas e Fibras de Aço. São Paulo, 2012. Dissertação (Mestrado de Engenharia Civil) - Escola Politécnica, Universidade de São Paulo. São Paulo, 2012.

FIGUEIREDO, A. D. Concreto Reforçado Com Fibras. São Paulo, 2011. Tese (Livre-Docência) Escola Concreto Politécnica, Universidade de São Paulo, São Paulo, 2011.

FIGUEIREDO, A. D. et al. Avaliação de Metodologia de Ensaio de Tubos de Concreto Reforçado Com Fibras Para Esgoto. Concreto e Construções, v. 34, n. 46, p. 44-51, 2007.

FIGUEIREDO, A. D.; TANESI, J.; NINCE, A. A. Concreto Com Fibras de Polipropileno. Téchne, v. 10, n. 66, p. 48-51, 2002.

FIGUEIREDO, A. D.; TORNERI, P. Efeitos da Ancoragem em Gancho de Fibras na Tenacidade dos Concretos. In: SIMPÓSIO EPUSP SOBRE ESTRUTURAS DE CONCRETO, 6., São Paulo, 2006. Anais... São Paulo, 2006.

KALIL, R.Z.; ESCARIZ, R. C.; FIGUEIREDO, A. D. Elaboração de Método de Ensaio Para Determinação do Teor de Fibras em Concreto Endurecido. In: CONGRESSO BRASILEIRO DO CONCRETO, 52, Fortaleza, 2010. Anais... São Paulo, 2010.

MOHAMED, N. Experimental and Numerical Study on Full-Scaleprecast Steel FibreReinforced Concrete Pipes. 2015. Tese (Doutorado em Ciência da Engenharia) - Escola de Pós-graduação e Pós-doutoramento da Universidade de Western Ontario, Canadá, 2015.

MOHAN, S. R.; PARTHIBAN, K. Strength and Behavior of Fly Ash Based Steel Fiber Reinforced Concrete Composite. International Journal of Civil and Structural Engineering, v. 2, n. 1, p.318-328, 2011.

MOHSEN, A. Evaluation of the Performance of Steel Fiber Reinforced Concrete Pipes Produced by Packerhead Method.Texas, 2014. Dissertação (Mestrado) - Faculdade de Ciência em Engenharia Civil, Universidade do Texas, Texas, 2014.

SILVA. J. L. da. Análise de Tubos Circulares de Concreto Armado Para o Ensaio de Compressão Diametral Com Base na Teoria da Confiabilidade. São Carlos, 2011. Tese (Doutorado em Engenharia Civil) - Escola de Engenharia de São Carlos, Universidade de São Paulo, São Carlos, 2011. 
SILVA. J. L. da.; EL DEBS, M.K. Influência da Bolsa no Comportamento Estrutural de Tubos de Concreto Armado Submetidos ao Ensaio de Compressão Diametral. In: CONGRESSO

BRASILEIRO DO CONCRETO, 51., Curitiba, 2009. Anais... Curitiba, 2009.

Marco Antonio Barbosa de Oliveira

Instituto Federal de Educação, Ciência e Tecnologia do Pará | Av. Almirante Barroso, de 41/42 a 653/654| Belém - PA - Brasil | CEP 66093-020 | Tel.: (091) 3201-1798 Ramal 1700 | E-mail: marco.barbosa@ifpa.edu.br

\section{Alcebíades Negrão Macêdo}

Instituto de Tecnologia | Universidade Federal do Pará | Rua Augusto Correa, 1, Guamá | Belém - PA - Brasil | CEP 66075-110 | Tel.: (91) 3201-7905 | E-mail: anmacedo@ufpa.br

\section{Bernardo Borges Pompeu}

Instituto de Tecnologia | Universidade Federal do Pará | E-mail: pompeu@ufpa.br

\section{Antonio Edurado Bezerra Cabral}

Departamento de Engenharia Estrutural e Construção Civil | Universidade Federal do Ceará | Campus do Pici, Bloco 728 | Fortaleza - CE Brasil | CEP 60455-900 | Tel.: (85) 3366-9607 | E-mail: eduardo.cabral@ufc.br

\section{Revista Ambiente Construído}

Associação Nacional de Tecnologia do Ambiente Construído

Av. Osvaldo Aranha, $99-3^{\circ}$ andar, Centro

Porto Alegre - RS - Brasil CEP $90035-190$

Telefone: +55 (51) 3308-4084

Fax: +55 (51) 3308-4054

www.seer.ufrgs.br/ambienteconstruido

E-mail: ambienteconstruido@ufrgs.br 